\title{
A Survey of Inhibitors for the Main Protease of Coronaviruses with the Potential for Development of Broad-Spectrum Therapeutics
}

\author{
Alyssa Sanders ${ }^{*}$, Samuel Ricci ${ }^{b}$, Sarab Uribe ${ }^{a}$, Bridget Boyle ${ }^{a}$, Brian Nepper ${ }^{b}$ \& Nathaniel Nuccia, \\ ${ }^{a}$ Department of Molecular \& Cellular Biosciences, Rowan University, Glassboro, NJ \\ ${ }^{b}$ Department of Physics \& Astronomy, Rowan University, Glassboro, NJ \\ bttps:// doi.org/10.33697/ ajur.2020.037
}

Students: sandersa8@students.rowan.edu,,riccis1@students.rowan.edu,uribes2@students.rowan.edu,bridget.boyle@jefferson.edu,nepperb@gmail.com Mentor:nucci@rowan.edu

\begin{abstract}
The coronaviruses plaguing humanity in the 21 st century share much in common: a spontaneous route of origin from wild animals, a propensity to take human life, and, importantly, a highly conserved set of biological machinery necessary for viral replication. Most recently, the SARS-CoV-2 is decimating economies around the world and has claimed over two million human lives, reminding the world of a need for an effective drug against present and future coronaviruses. To date, attempts to repurpose clinically approved antiviral medications show minimal promise, highlighting the need for development of new antiviral drugs. Nucleotide analog inhibitors are a promising therapeutic candidate, but early data from clinical studies suggests these compounds have limited efficacy. However, novel compounds targeting the main protease responsible for critical steps in viral assembly are gaining considerable interest because they offer the potential for broad-spectrum coronavirus therapy. Here, we review the literature regarding potential inhibitors for the main protease of coronaviruses, especially SARS-CoV-2, analyze receptor-drug interactions, and draw conclusions about candidate inhibitors for future outbreaks. Promising candidates for development of a broad-spectrum coronavirus protease inhibitor include the neuraminidase inhibitor $3 \mathrm{~K}$, the peptidomimetic inhibitor $11 \mathrm{a}$ and $11 \mathrm{~b}$, the $\alpha$-ketoamide inhibitor 13b, the aldehyde prodrug, and the phosphate prodrug developed by Pfizer. In silico and in vitro analyses have shown that these inhibitors strongly interact with the active site of the main protease, and to varying degrees, prevent viral replication via interactions with the largely conserved active site pockets.
\end{abstract}

\section{KEYWORDS}

Severe Acute Respiratory Syndrome Coronavirus; Middle East Respiratory Syndrome Coronavirus; Severe Acute Respiratory Syndrome Coronavirus 2; Replicase Polypeptide; Protease; Neuraminidase Inhibitor; Peptidomimetic Inhibitor; $\alpha$-Ketoamide Inhibitor; Molecular Docking

\section{INTRODUCTION}

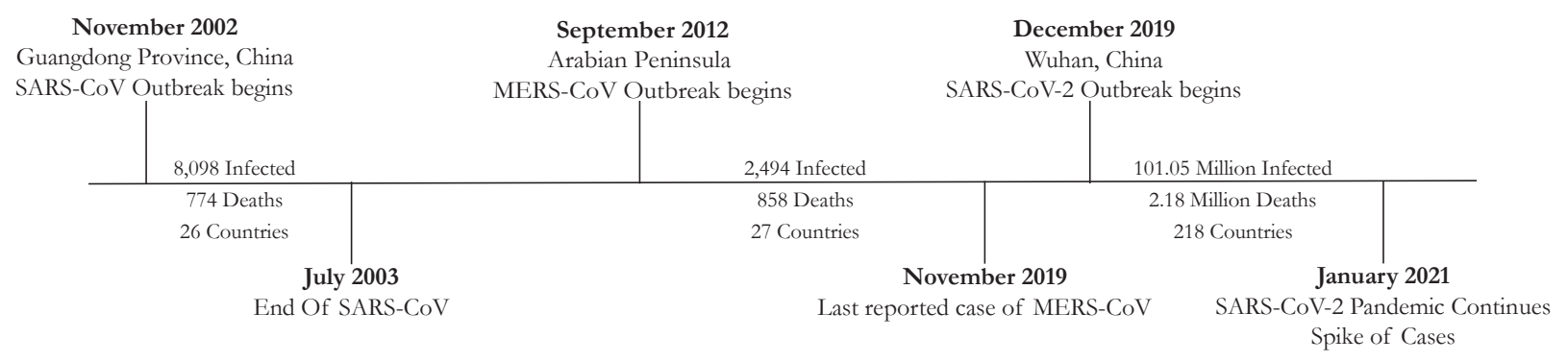

Figure 1. A timeline of the recent coronavirus outbreaks, with the case total and death total from the World Health Organization. ${ }^{1-3}$ Reported data are from January 29, 2021.

Severe acute respiratory syndrome coronavirus (SARS-CoV), Middle East respiratory syndrome coronavirus (MERS-CoV), and severe acute respiratory syndrome coronavirus 2 (SARS-CoV-2) are three highly pathogenic coronaviruses that have emerged in the 21 st century. Each of these have zoonotic origins, and are genetically similar to coronaviruses in bats around the world.4, 5 As seen in Figure 1, SARS-CoV was the first outbreak and originated in Guangdong Province, China, in November 2002. The SARS-CoV outbreak officially ended in July 2003. ${ }^{6}$ Nine years later, MERS-CoV emerged in the Arabian Peninsula and continues to infect people today. ${ }^{7}$ Both SARS-CoV and MERS-CoV spread to over two dozen countries, infected thousands of people, and have estimated death rates of 10 and $40 \%$, respectively. ${ }^{5}, 6$ The most recent outbreak, SARS-CoV-2, has spread globally to nearly 
every nation and territory with confirmed cases in the tens of millions and more than two million deaths as of January, 2021. The estimated fatality rate for SARS-CoV-2 is 3.3\% globally. ${ }^{10}$ Prior to SARS-CoV, known coronavirus infections in humans presented mild symptoms and were isolated to specific regions of the world. ${ }^{11}$ SARS-CoV-2, however, shows the potential for coronavirus outbreaks to reach pandemic proportions. Taken together, the evidence of zoonotic origins and capability of global infection support the possibility of another pandemic-level coronavirus emerging. A robust understanding of the coronavirus biology is therefore vital to the safety and wellbeing of the human population.

Despite the different time periods and severity of the outbreaks mentioned, the coronaviruses display a strong degree of genetic and structural conservation. ${ }^{12}$ SARS-CoV, MERS-CoV, and SARS-CoV-2, are positive-sense, single-stranded RNA viruses with genomes of $\sim 30,000$ nucleotides. ${ }^{13-15}$ Approximately two-thirds of this genome encodes the replicase machinery for the coronavirus. ${ }^{16}$ The replicase gene consists of two open reading frames (ORF), ORF1a and ORF1b. ORF1a is found upstream and encodes for polyprotein (pp) 1a. When transcribed together, ORF1a and ORF1b encode a larger polyprotein, pp1ab. ${ }^{16}$ The polyproteins contain the chymotrypsin-like $\left(\mathrm{M}^{\mathrm{Pro}}\right.$ or $\left.\mathrm{CL}^{\mathrm{Pro}}\right)$ and papain-like $\left(\mathrm{PL}^{\mathrm{Pro}}\right)$ proteases which cleave the polyprotein into 16 non-structural proteins (Nsp). ${ }^{17}$ The PL ${ }^{\text {Pro }}$ cleaves at five sites, working in the N-terminal direction, Nsp1-4, and the ${ }^{\text {Pro }}$, which is Nsp5, cleaves the polyprotein at eleven sites working in the C-terminal direction. $\mathrm{M}^{\text {Pro }}$ auto cleaves itself from the polyprotein and subsequently cleaves Nsp6-16 (Figure 2). ${ }^{18}$ These non-structural proteins form two major complexes: the cytoplasmic enzyme complex and the replicase complex. ${ }^{14,16} \mathrm{PL}^{\text {Pro }}$ cleaves Nsp1 which is responsible for suppressing the host gene expression by degrading the host cell's RNA, improving viral gene expression efficiency. ${ }^{20}$ This occurs by Nsp1 binding to the $40 \mathrm{~S}$ ribosomal subunit in the host cell and inactivating it. This suppresses the cap-dependent and internal ribosome entry site (IRES)-mediated translation, protecting the RNA of the coronavirus. ${ }^{20}$ PL Pro also cleaves Nsp2 which has an unclear function. ${ }^{18}$ In previous studies, the deletion of Nsp2 resulted in decrease viral RNA synthesis and growth, inferring that Nsp2 plays a crucial role in viral RNA synthesis, although the specific mechanism of action requires further research. Nsps3-6 work together to form double membrane vesicles involved in RNA synthesis. Nsp7 and 8 form a large super complex that supports viral replication. ${ }^{18,19}$ Nsp9 plays a role in the binding of ssRNA and dsDNA and affects viral growth. ${ }^{20,21} \mathrm{Nsp} 10$ and 11 also play a role in viral RNA synthesis, and Nsp10 forms a part of the viral mRNA cap methylation complex. ${ }^{15,22} \mathrm{Nsp} 12$ is responsible for priming the dependent RNA polymerase. ${ }^{15,23} \mathrm{Nsp} 13$, a helicase with RNA and DNA unwinding capabilities, possesses dNTPase activity, helping form the 5' cap of viral mRNA. ${ }^{24,}{ }^{25} \mathrm{Nsp} 14$ removes one nucleotide at a time from viral ssRNA and dsDNA. ${ }^{29}$ The function of Nsp15 is unknown, however the role of Nsp16 is to add Nsp10 and Nsp14 to form the mRNA cap methylation complex. ${ }^{18}$ PL ${ }^{\text {Pro }}$ cleaves Nsps1-4, which are proteins necessary for colonizing, and the $\mathrm{M}^{\text {Pro }}$ cleaves the Nsps needed to support the replication machinery.

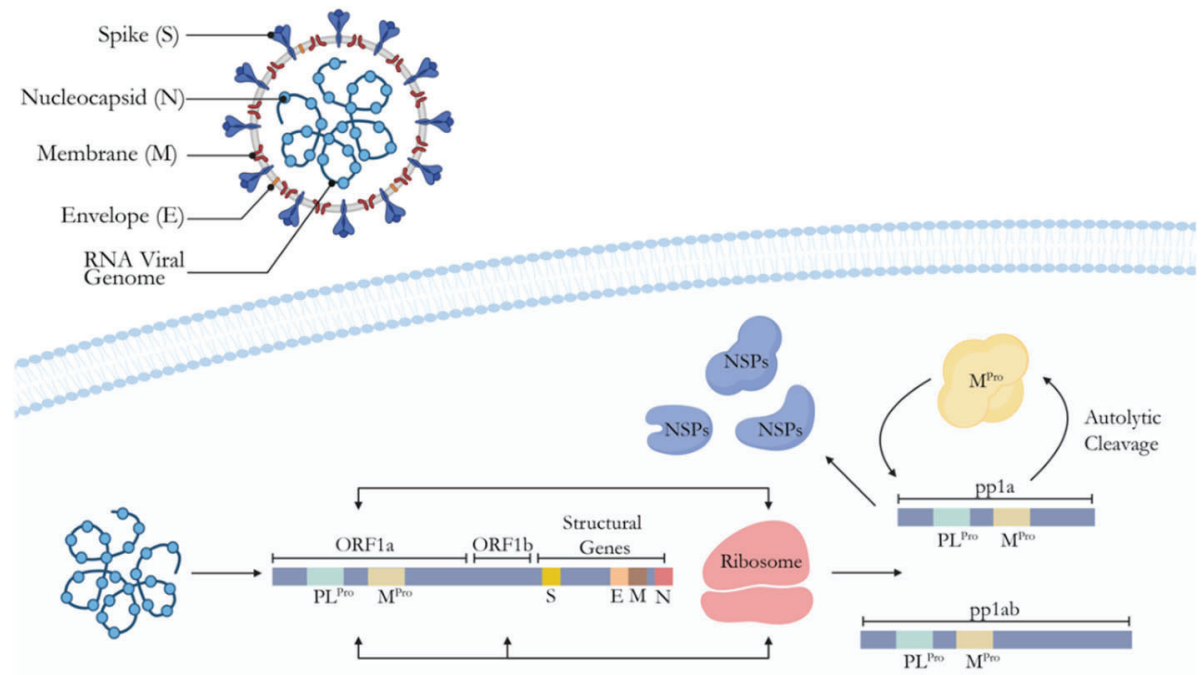

Figure 2. Coronavirus replication pathway. After inserting the viral RNA, ORF1a or ORF1a and ORF1b are translated into the polyproteins pp1a or pp1ab, respectively. The main protease, $\mathrm{M}^{\text {Pro }}$, automatically cleaves itself from the translated polyprotein and begins to cleave nonstructural proteins from the remainder of the protein. The nonstructural proteins then combine to form the necessary replication machinery. This image was created with BioRender.com. 
Although the $\mathrm{M}^{\text {Pro }}$ and PL ${ }^{\text {Pro }}$ both cleave Nsps, inhibiting the $\mathrm{M}^{\text {Pro }}$ has some advantages over PL Pro inhibition: the $\mathrm{M}^{\text {Pro }}$ has a larger role in viral replication, it displays high genetic and structural conservation, and there are no human analogues, ${ }^{30,31}$ thus an inhibitor would be less likely to target human proteins and lead to unwanted side effects. Additionally, the spike protein - the protein necessary for the coronavirus to attach to human epithelial cells - is a popular target for drug design, but the efficacy of this target is limited because flexible glycans shield the protein from molecular detection. ${ }^{2}$

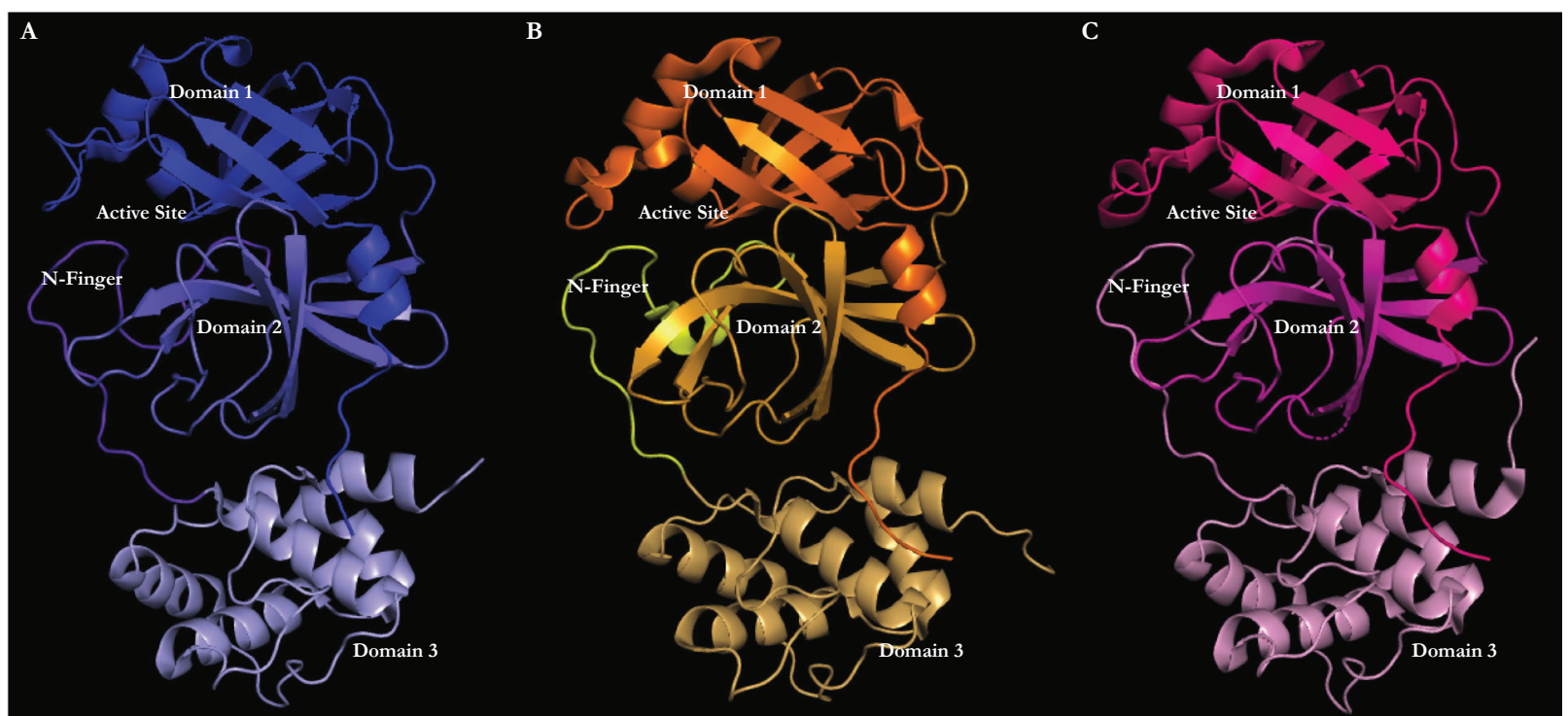

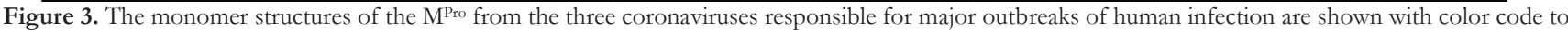
distinguish their structural domains. A. SARS-CoV M Pro (PDB: 1UK3)33: Domain I (residues 1-97), Domain II (98-175), Domain III (200-306), N-finger (176199). B. MERS-CoV M ${ }^{\text {Pro }}$ (PDB: 4WME) ${ }^{34}$ : Domain I (1-97), Domain II (98-178), Domain III (201-306), N-finger (179-200). C. SARS-CoV-2 M ${ }^{\text {Pro }}$ (PDB: 6YB7) ${ }^{35}$ : Domain I (1-97), Domain II (98-175), Domain III (200-306), N-Finger (176-199). This figure was made through the use of PyMOL. ${ }^{36}$

The $\mathrm{M}^{\text {Pro }}$ is catalytically active as a homodimer, and each monomer has three domains, Figure 3. Domains I and II include antiparallel $\beta$-sheets and form the active site of the protease. Domain III includes five $\alpha$-helices in a globular cluster and mediates dimerization. Interactions between the helices of monomers are the primary driver of dimerization. The C-terminal domain III is linked to the N-terminal domains I and II via a long loop referred to as the N-finger.

As shown in Figure 3, the structures of the SARS-CoV, MERS-CoV, and SARS-CoV-2 M ${ }^{\text {Pro }}$ are highly similar. SARS-CoV and SARS-CoV-2 are genetically nearly identical, sharing $96 \%$ of their nucleotide sequence. ${ }^{37}$ MERS-CoV shares $87 \%$ genetic similarity with SARS-CoV-2. ${ }^{38}$ There are 108 non-conservative and 45 conservative amino acid mutations between the main proteases of SARS-CoV and MERS-CoV, Figure 4. A considerable portion, 43\%, of non-conservative mutations are found in domain III, showing active site conservation. This observation is further corroborated by a lower root mean square deviation in atomic position of overlays of domains I and II compared to domain III, 0.311, 0.455, and $1.062 \AA$ respectively..$^{39}$ Despite the comparatively larger variance of the MERS-CoV M $\mathrm{M}^{\text {Pro }}$, only one significant structural change is evident. The N-finger of MERS$\mathrm{CoV} \mathrm{M}^{\text {Pro }}$ is distinct from the other two, demonstrated by the addition of an $\alpha$-helix (Figure 5, shown in yellow). There are only five non-conservative mutations and four conservative amino acid mutations between SARS-CoV and SARS-CoV-2. The only evident structural difference is caused by a non-conservative mutation of Ala46 in SARS-CoV M ${ }^{\text {Pro }}$ to Ser in MERS-CoV and SARS-CoV-2 $\mathrm{M}^{\text {Pro }}$ in the first domain. This replacement of a hydrophobic side chain with a hydrophilic one induces the change of a small $\alpha$-helical turn to an apparently more flexible loop (Figure 5, at the active site on the outside of domain I). The N-finger is crucial for catalytic activity, but not for dimerization. ${ }^{38}$ Mutated proteases lacking the $\mathrm{N}$-finger show C-terminal mediated dimerization but cannot cleave the substrate. ${ }^{38}$ Given the strongly conserved nature of the flexible $\mathrm{N}$-finger, the extension may regulate the active site's exposure to ligands. Although this is not fully understood, the specific mechanism warrants further study. ${ }^{40}$ All three coronaviruses have minor genetic and amino acid differences, MERS-CoV to a greater extent than SARS-CoV to SARS-CoV-2, but there is an important structural and functional conservation shared in the makeup of the enzymes' active sites. ${ }^{40}$ 
Structural features found to contribute to the catalytic mechanism of $\mathrm{M}^{\text {Pro }}$ are highly conserved across coronavirus lines. A Cys145-His41 catalytic dyad is the central functional unit of the protease. Mutation of either the Cys or His to Ala leaves the enzyme nonfunctional. ${ }^{41}$ Catalysis begins with the binding of the polypeptide substrate to the enzyme, forming a Michaelis complex. Cleavage of the substrate at the conserved Glu-Ala (or Ser) bond triggers the release of the N-terminal half of the peptide. The C-terminal end of the peptide substrate acylates the active site, and the His 41 residue acts as a base in the deacylation step, releasing the C-terminal end. ${ }^{42}$ A GSCGS motif, Figure 4 and Figure 5, is essential to catalytic activity; mutations in this motif towards smaller, hydrophobic amino acid residues result in a sharp reduction in catalytic efficiency. ${ }^{39}$ The motif starts the catalytic process by forming hydrogen bonds with pp1a. In tandem with the GSCGS motif, all three $\mathrm{M}^{\text {Pro }}$ sequences contain a partial negative charge cluster composed of amino acid residues Arg40, Tyr54, and Asp190. ${ }^{39}$ Mutations of Asp190 to nonpolar and polar-uncharged amino acids fail to cleave the peptide substrate, demonstrating the importance of the negative charged group. Arg40 interacts with, and potentially balances, the negative charge associated with Asp190. Mutations of Arg40 to aliphatic residues inhibit the enzyme's ability to successfully cleave the peptide. Tyr54 directly interacts with Arg30 via $\pi$-cation interactions, limiting the negative charge, so the resultant charge of these interactions is partially negative. ${ }^{39}$ Thermodynamic simulations support the need for a conserved water molecule to link the GSCGS motif and partial negative charge cluster. ${ }^{39}$ Although these analyses were performed on SARS-CoV and MERS-CoV only, these findings provide meaningful insight to the catalytic mechanism of the coronavirus's main protease, and both the motif and partial negative charge cluster, are present in the SARS-CoV-2 $\mathrm{M}^{\text {Pro. }}$.

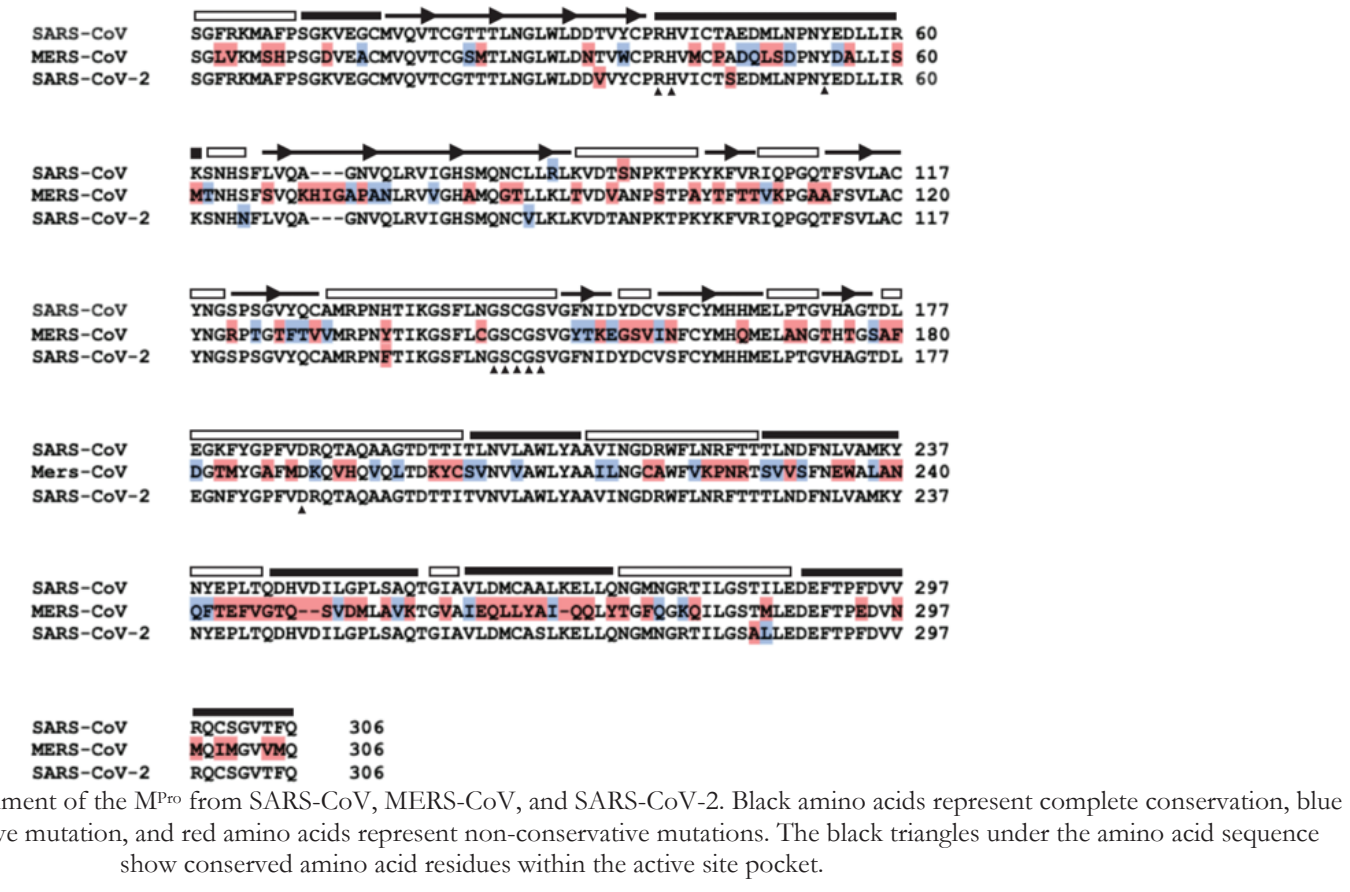

The active site, formed between domains I and II and the N-finger, is vital for the proteases' function and has become an increasing target for inhibitor design. ${ }^{43}$ Targeting the active site would prevent cleavage of non-structural proteins from pp1a and pp1ab. ${ }^{30,42}$ As shown in Figure 5, there are four unique subsites, $S_{1}, S_{1}, S_{2}$, and $S_{4}$, which independently interact with the polypeptide, increasing the overall binding affinity. The $\mathrm{S}_{1}$ subsite spans parts of domains I and II of the $\mathrm{M}^{\mathrm{Pro}}$, whereas the $\mathrm{S}_{1}{ }^{\text {, }}$ subsite is strictly in domain $\mathrm{I}$. The $\mathrm{S}_{2}$ subsite is located between domain I and the $\mathrm{N}$-finger and is comprised of those resulting amino acids. The $\mathrm{S}_{4}$ subsite is located between the $\mathrm{N}$-finger and domain II. The location of these subsites is conserved across strains, indicating the importance of the overall active site structure. In the $S_{1}$ subsite, the polypeptide backbone displays multiple hydrogen bonding donors and acceptors available for bonding with a potential inhibitor. ${ }^{30}$, 42 Another key characteristic of the $S_{1}$ subsite is the oxyanion hole, which is made up of amino acid residues 138 through 145 for SARS-CoV and SARS-CoV-2, and residues 141 through 148 for MERS-CoV. The hole, also referred to as the oxyanion loop, donates two hydrogen atoms during dimerization, further stabilizing the transition state of the catalysis reaction. ${ }^{45}$ Subsite $\mathrm{S}_{1}$ ' has three crucial, exposed amino acid residues, His41, Cys145, and Gly143.45 Subsite $S_{1}$ ' has three crucial, exposed amino acid residues, His41, Cys145, and Gly143. Inhibitor interaction with these pocket residues gives rise to potent antiviral activity. The $S_{2}$ and $S_{4}$ pockets are typically large and are lined by hydrophobic side chains. Previous studies show that drug compounds with bulky, hydrophobic structures interact 
with these pockets to further increase binding affinity. The $\mathrm{S}_{2}$ and $\mathrm{S}_{4}$ pockets have hydrogen bonding at the carboxyl oxygen of His164, providing an anchor point for these inhibitors.

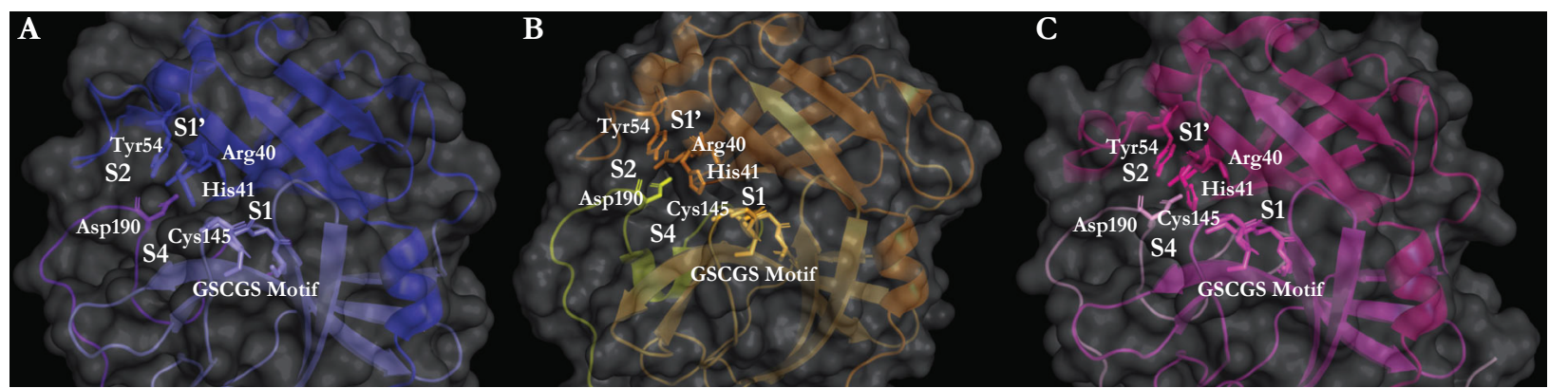

Figure 5. Conserved structures within the active sites of A. SARS-CoV (PDB: 1UK3) ${ }^{33}$, B. MERS-CoV (PDB: 4WME) ${ }^{34}$, and C. SARS-CoV-2 (PDB: 6YB7) ${ }^{35}$ main proteases. Shown are the cysteine-histidine dyad, the GSCGS motif, and the partial negative charge cluster. The subsites of the active site pocket are also shown. This figure was with PyMOL. ${ }^{36}$

\section{POTENTIAL INHIBITORS}

Efforts to identify inhibitors against SARS-CoV-2 have involved both repurposing previously discovered antiviral drugs and development of novel inhibitors. Repurposed inhibitors, used for treatment of diseases such as HIV, hepatitis, influenza or asthma, include Atazanavir ${ }^{46}$, Darunavir ${ }^{47}$, Ebselen ${ }^{48,} 4$, Lopinavir in combination with Ritonavir ${ }^{50-52}$, Boceprevir ${ }^{53}$, Oseltamivir ${ }^{54}$, calpain inhibitors II and XII ${ }^{53}$, and Montelukast ${ }^{55}$, Table 1.

\begin{tabular}{|c|c|c|c|c|c|c|}
\hline & Inhibitor & Classification & Viral Line & Method & $\mathrm{IC}_{50}$ & Reference \\
\hline \multirow{9}{*}{ 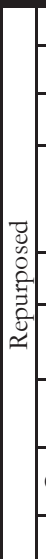 } & Atazanavir & HIV Inhibitor & SARS-CoV-2 & In vitro & NR & 46 \\
\hline & Darunavir & HIV Inhibitor & SARS-COV-2 & Clinical Trial & NA & 47 \\
\hline & Ebselen & Bi-Polar Disorder & SARS-CoV-2 & In vitro & $.67 \mu \mathrm{M}$ & 48,49 \\
\hline & Lopinavir/ Ritonavir & HIV Antiviral & $\begin{array}{l}\text { SARS-CoV } \\
\text { MERS-CoV } \\
\text { SARS-CoV-2 }\end{array}$ & Clinical Trial & NR & $50-52$ \\
\hline & Boceprevir & Hepatitis Inhibitor & SARS-CoV-2 & In vitro & $4.13 \mu \mathrm{M}$ & 53 \\
\hline & Oseltamivir & Influenza Inhibitor & SARS-CoV-2 & \begin{tabular}{c|} 
In vitro \\
Clinical Trial
\end{tabular} & $>100 \mu \mathrm{M}$ & 54 \\
\hline & Calpain Inhibitor II & Calpain Inhibitor & SARS-CoV-2 & In vitro & $2.07 \mu \mathrm{M}$ & 53 \\
\hline & Calpain Inhibitor XII & Calpain Inhibitor & SARS-CoV-2 & In vitro & $0.49 \mu \mathrm{M}$ & 53 \\
\hline & Montelukast & Anti-asthma & SARS-CoV-2 & Computational & NR & 55 \\
\hline \multirow{8}{*}{$\begin{array}{l}\overrightarrow{0} \\
0 \\
0 \\
z\end{array}$} & Compound 6d & Peptidomimetic inhibitor & $\begin{array}{l}\text { SARS-CoV } \\
\text { MERS-CoV }\end{array}$ & In vitro & $\begin{array}{l}1.7 \mu \mathrm{M} \\
4.7 \mu \mathrm{M}\end{array}$ & 57 \\
\hline & $3 \mathrm{~K}$ & Neuraminidase (NA) Inhibitor & $\begin{array}{l}\text { SARS-CoV } \\
\text { MERS-CoV }\end{array}$ & In vitro & $\begin{array}{c}\text { SARS } 6.4 \\
\text { MERS } 5.8\end{array}$ & 44 \\
\hline & $11 \mathrm{a}$ & Peptidomimetic Inhibitors & SARS-CoV-2 & In vitro & $0.053 \mu \mathrm{M}$ & 61 \\
\hline & $11 \mathrm{~b}$ & Peptidomimetic Inhibitors & SARS-CoV-2 & In vitro & $.040 \mu \mathrm{M}$ & 61 \\
\hline & $13 \mathrm{a}$ & Alpha-Ketoamides Inhibitor & SARS-CoV-2 & In vitro & $2.39 \mu \mathrm{M}$ & 43,65 \\
\hline & $13 b$ & Alpha-Ketoamides Inhibitor & SARS-CoV-2 & In vitro & $0.67 \mu \mathrm{M}$ & 43,65 \\
\hline & GC-376 & Aldehyde Prodrug & SARS-CoV-2 & In vitro & $0.03 \mu \mathrm{M}$ & 63 \\
\hline & PF-07304814 & Phosphate Prodrug & $\begin{array}{c}\text { SARS-CoV } \\
\text { SARS-CoV-2 }\end{array}$ & $\begin{array}{c}\text { In vitro } \\
\text { Clinical Trial }\end{array}$ & NR & 62 \\
\hline
\end{tabular}

Table 1. A selection of the inhibitors that have been tested on $\mathrm{M}^{\text {Pro }}$.

The repurposed inhibitors that have been tested in clinical trials show little efficiency for inhibiting the coronavirus $\mathrm{M}^{\mathrm{Pro}}$. The HIV inhibitor, Darunavir did not have an anti-viral effect on SARS-CoV-2 and is a poor therapeutic option for the M ${ }^{\text {Pro }}$ of coronaviruses. ${ }^{47}$ In the clinical trial using Lopinavir in combination with ritonavir, hospitalization times and symptoms were 
comparable to the control. ${ }^{51}$ On day 28 of this combination therapy, patients' SARS-CoV-2 RNA levels plateaued at $40 \%$ of the viral load documented at the start of the trial. This led to the belief that the combination of Lopinavir and ritonavir does not inhibit the viral $\mathrm{M}^{\text {Pro. }}$. The patients treated with Lopinavir and Ritonavir suffered adverse side effects and the trial was halted.51 Though some docking experiments suggest these repurposed inhibitors should work, they have consistently shown insignificant improvements in clinical outcomes, at best. The evidence now strongly indicates that repurposed drugs show marginal promise and present no guarantee of working on future coronaviruses. Therefore, designing and testing novel compounds and inhibitors is crucial in the fight against coronavirus related illnesses. Some novel inhibitors that show promise include neuraminidase (NA) inhibitors $(3 \mathrm{~K})^{44}$, multiple peptidomimetic inhibitors like compound 6d, 11a, and 11b 56-61, phosphate prodrug PF-07304814 62, an aldehyde prodrug GC-376 ${ }^{63}$, and lastly alpha-ketoamides inhibitors $13 \mathrm{a}$ and $13 \mathrm{~b}^{64}$, Table 1 . The novel inhibitors that seem to have the most promise based on our analysis of the reported $\mathrm{IC}_{50}$ values are the $3 \mathrm{~K}$ inhibitor, 11a, 11b, 13a, GC-376, and PF07304814.

\begin{tabular}{|c|c|c|c|c|}
\hline Inhibitor & Covalent Bonds & Hydrogen Bonds & Hydrophobic Interactions & Reference \\
\hline $3 \mathrm{~K}$ - SARS & None & Len141 $\left(\mathrm{S}_{1}\right), \operatorname{Ser} 144\left(\mathrm{~S}_{1}\right), \operatorname{His} 163\left(\mathrm{~S}_{1}\right), \operatorname{Glu} 166\left(\mathrm{~S}_{1}\right)$ & $\begin{array}{l}\text { His41 }\left(\mathrm{S}_{1}{ }^{\prime}\right), \operatorname{Leu} 49\left(\mathrm{~S}_{2}\right), \operatorname{Gln} 192\left(\mathrm{~S}_{4}\right) \\
\text { Leu170 }\left(\mathrm{S}_{4}\right), \mathrm{Gln} 195\left(\mathrm{~S}_{4}\right), \operatorname{Val193}\left(\mathrm{S}_{4}\right)\end{array}$ & 44 \\
\hline $3 \mathrm{~K}-\mathrm{MERS}$ & None & $\operatorname{Ser147}\left(\mathrm{S}_{1}{ }^{\prime}\right), \operatorname{His} 166\left(\mathrm{~S}_{1}\right), \operatorname{Glu} 169\left(\mathrm{~S}_{1}\right)$ & $\begin{array}{l}\text { His41 }\left(\mathrm{S}_{1}\right) \text {, Leu } 49\left(\mathrm{~S}_{2}\right), \operatorname{Gln} 192\left(\mathrm{~S}_{4}\right) \text {, } \\
\text { Leu } 170\left(\mathrm{~S}_{4}\right), \operatorname{Gln} 195\left(\mathrm{~S}_{4}\right), \operatorname{Val193}\left(\mathrm{S}_{4}\right)\end{array}$ & 44 \\
\hline $11 \mathrm{a}$ & Cys145 $\left(\mathrm{S}_{1}\right)^{\prime}$ & Cys145 $\left(\mathrm{S}_{1}\right), \operatorname{Gly} 143\left(\mathrm{~S}_{1}\right), \operatorname{His} 163\left(\mathrm{~S}_{1}\right), \underline{\operatorname{Glu} 166}\left(\mathrm{~S}_{1}\right)$, Phe $140\left(\mathrm{~S}_{1}\right)$ & $\begin{array}{l}\operatorname{Met} 49\left(\mathrm{~S}_{2}\right), \operatorname{Try} 54\left(\mathrm{~S}_{2}\right), \operatorname{Met} 165\left(\mathrm{~S}_{2}\right) \\
\text { Asp187 }\left(\mathrm{S}_{2}\right), \operatorname{Pro} 168\left(\mathrm{~S}_{4}\right), \mathrm{G} \ln 189\left(\mathrm{~S}_{4}\right)\end{array}$ & 61 \\
\hline $11 b$ & Cys145 ( $\left.\mathrm{S}_{1}\right)^{\prime}$ & $\begin{array}{c}\mathrm{Gln} 189\left(\mathrm{~S}_{4}\right), \operatorname{Gly} 143\left(\mathrm{~S}_{1}\right), \text { Cys 145 }\left(\mathrm{S}_{1}\right), \operatorname{His} 163\left(\mathrm{~S}_{1}\right) \\
\text { His164 }\left(\mathrm{S}_{1}\right), \operatorname{Ph} 140\left(\mathrm{~S}_{1}\right), \underline{\operatorname{Gl} 166}\left(\mathrm{~S}_{1}\right)\end{array}$ & $\begin{array}{l}\text { His41 }\left(\mathrm{S}_{1}\right), \operatorname{Met} 49\left(\mathrm{~S}_{2}\right), \operatorname{Met} 165\left(\mathrm{~S}_{4}\right) \\
\text { Val186 }\left(\mathrm{S}_{2}\right), \operatorname{Tyr} 54\left(\mathrm{~S}_{2}\right), \operatorname{Asp} 187\left(\mathrm{~S}_{2}\right)\end{array}$ & 61 \\
\hline $13 \mathrm{~b}$ & Cys145 ( $\left.\mathrm{S}_{1}\right)$ & $\begin{array}{l}\text { His41 }\left(\mathrm{S}_{1}{ }^{\prime}\right), \operatorname{Gly} 143\left(\mathrm{~S}_{1}{ }^{\prime}\right), \operatorname{Ser} 144\left(\mathrm{~S}_{1}\right), \operatorname{Glu166}\left(\mathrm{S}_{1}\right), \operatorname{Phe} 140\left(\mathrm{~S}_{1}\right) \\
\operatorname{Gly} 143\left(\mathrm{~S}_{1}{ }^{\prime}\right), \operatorname{Cys} 145\left(\mathrm{~S}_{1}{ }^{\prime}\right), \operatorname{His} 164\left(\mathrm{~S}_{2}\right), \operatorname{Thr} 26\left(\mathrm{~S}_{1}{ }^{\prime}\right), \operatorname{His} 172\left(\mathrm{~S}_{4}\right)\end{array}$ & $\begin{array}{c}\operatorname{Met165}\left(\mathrm{S}_{4}\right), \operatorname{Gln} 189\left(\mathrm{~S}_{4}\right), \operatorname{His} 41\left(\mathrm{~S}_{1}\right), \\
\operatorname{Met} 49\left(\mathrm{~S}_{2}\right), \operatorname{Asp} 187\left(\mathrm{~S}_{2}\right), \operatorname{Asn} 142\left(\mathrm{~S}_{4}\right), \\
\text { Pro168 }\left(\mathrm{S}_{4}\right)\end{array}$ & 43,65 \\
\hline GC-376 & Cys145 $\left(\mathrm{S}_{1}\right)$ & $\begin{array}{l}\text { Gly143 }\left(S_{1}{ }^{\prime}\right) \text {, Ser144 }\left(S_{1}{ }^{\prime}\right) \text {, His163 }\left(\mathrm{S}_{1}\right), \text { Cys } 145\left(S_{1}{ }^{\prime}\right), \operatorname{Glu166}\left(\mathrm{S}_{1}\right), \\
\text { Glu166 }\left(\mathrm{S}_{1}\right), \text { Phe140 }\left(S_{1}\right), \mathrm{Gln} 189\left(\mathrm{~S}_{4}\right), \operatorname{His} 41\left(\mathrm{~S}_{1}{ }^{\prime}\right)\end{array}$ & His41 (S1), Met49 (S2), Met169 $\left(\mathrm{S}_{2}\right)$ & 63 \\
\hline PF-07304814 & Cys145 $\left(\mathrm{S}_{1}{ }^{\prime}\right)$ & $\begin{array}{c}\text { Met165 }\left(S_{4}\right), \operatorname{Cys} 145\left(\mathrm{~S}_{1}\right), \operatorname{His} 164\left(\mathrm{~S}_{2}\right), \operatorname{Phe} 140\left(\mathrm{~S}_{1}\right), \operatorname{His} 163\left(\mathrm{~S}_{1}\right), \\
\operatorname{Glu165}\left(\mathrm{S}_{1}\right), \operatorname{Glu166}\left(\mathrm{S}_{1}\right)\end{array}$ & $\begin{array}{l}\text { His41 }\left(\mathrm{S}_{1}\right), \operatorname{Met} 49\left(\mathrm{~S}_{2}\right), \text { Tyr54 }\left(\mathrm{S}_{2}\right) \\
\quad \text { Pro168 }\left(\mathrm{S}_{4}\right), \operatorname{Asp} 187\left(\mathrm{~S}_{2}\right)\end{array}$ & 62 \\
\hline
\end{tabular}

Table 2. Potential novel inhibitors for the $\mathrm{M}^{\text {Pro }}$ of coronaviruses and the interactions that they have with the amino acids (sub pockets) of the active site as reported by the cited references. Hydrogen bond lists indicate protein-inhibitor H-bonds formed with side chains only (plain text), with backbone only (italicized), or with both backbone and side chains (italicized and underlined). These interaction were determined or confirmed by our analysis of the $\mathrm{M}^{\text {Pro-drug structures }}$ using PyMOL. ${ }^{36}$

\section{A Neuraminidase (NA) Inbibitor (3k)}

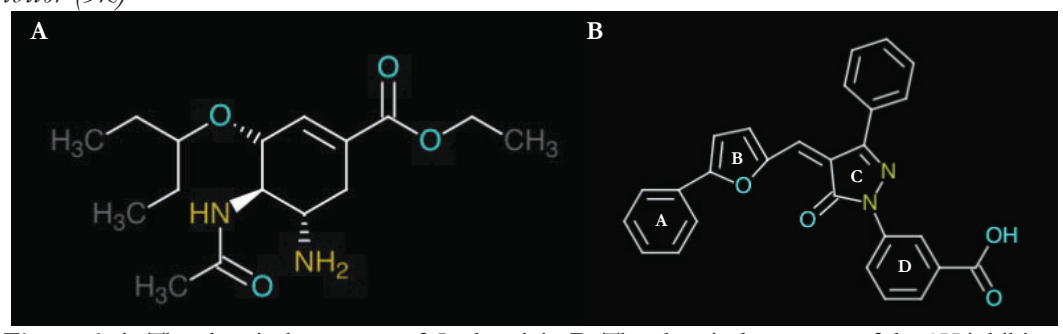

Figure 6. A. The chemical structure of Oseltamivir. B. The chemical structure of the $3 \mathrm{~K}$ inhibitor.

Neuraminidase (NA) inhibitors are antiviral agents that work against both influenza A and influenza B. These types of inhibitors work by blocking the neuraminidase enzyme - which functions to free viruses from infected cells contributing to further spread to prevent further infection. ${ }^{66}$ Two NA inhibitors used to inhibit the $\mathrm{M}^{\text {Pro }}$ of coronaviruses are Oseltamivir and $3 \mathrm{~K}$ (Figure 6). ${ }^{44}$, 54 The most significant structural change between Oseltamivir and the $3 \mathrm{~K}$ inhibitor is the expanded aromatic functionalization in $3 \mathrm{~K}$. The increased size and hydrophobicity of the $3 \mathrm{~K}$ inhibitor predicts the increased performance of $3 \mathrm{~K}$ over Oseltamivir is a result of the bulky, hydrophobic subgroups. Both Oseltamivir and the $3 \mathrm{~K}$ inhibitor are capable of forming six hydrogen bonds with the active site.

Tan, et al., performed molecular docking and in vitro studies of Oseltamivir (Figure 6A), a competitive neuraminidase inhibitor widely used in the clinic to treat influenza A and B, on several structures found within the SARS-CoV-2.54 In silico analysis predicted a potential binding energy of $-7.5 \mathrm{kcal} / \mathrm{mol}$ for Oseltamivir carboxylic acid and the active site of the SARS-CoV-2 $\mathrm{M}^{\text {Pro }} .{ }^{54}$ Successful binding in silico for this repurposed inhibitor did not, however, translate to antiviral activity with in vitro analysis providing an $\mathrm{IC}_{50}$ greater than $100 \mu \mathrm{M} .{ }^{54}$ The high $\mathrm{IC}_{50}$ value indicated an ineffective inhibition of Oseltamivir to the $\mathrm{M}^{\text {Pro }}$. However, a previous study by Kumar, et al., experimentally examined 19 different NA inhibitors in complex with SARS-CoV and 
MERS-CoV, ${ }^{44}$ and determined the $\mathrm{IC}_{50}$ values for the inhibitors via a fluorometric assay. A fluorogenic peptide is placed in solution with the $\mathrm{M}^{\text {Pro }}$ and cleavage of the peptide increases the fluorescence intensity, allowing for a quantitative measure of enzyme efficacy. The most promising compound was $3 \mathrm{~K}$, shown in Figure 6B. The 3K inhibitor in complex with SARS-CoV $\mathrm{M}^{\text {Pro }}$ shows an $\mathrm{IC}_{50}$ of $6.4 \pm 1.2 \mu \mathrm{M}$, and an $\mathrm{IC}_{50}$ of $5.8 \pm 1.6 \mu \mathrm{M}$ with MERS-CoV $\mathrm{M}^{\text {Pro }}$. Modeling of $3 \mathrm{~K}$ binding showed that the inhibitor does not occupy the $\mathrm{S}_{1}$ ' subsite. ${ }^{44}$ Instead, the phenyl group shows a preference for the hydrophobic pocket at $\mathrm{S}_{4}$. However, the phenyl group had a tighter fit in the $\mathrm{S}_{4}$ pocket of the MERS-CoV MPro due to the smaller pocket size in this variant. The hydrophobicity of ring A creates a strong binding interaction with the $\mathrm{S}_{2}$ subsite, Table 2 . In the $\mathrm{S}_{1}$ pocket of $\mathrm{SARS}-\mathrm{CoV}$, the $3 \mathrm{~K}$ inhibitor forms hydrogen bonds with Ser144 and Leu141. In MERS-CoV, the 3K inhibitor forms hydrogen bonds in the $\mathrm{S}_{1}$ pocket with Ser147 and Glu169. The promise of $3 \mathrm{~K}$ shown in this study requires confirmation using cell-based assays to further verify the predicted effects. Given the strong similarities between the $\mathrm{M}^{\text {Pro }}$ active sites, NA inhibitors based on the $3 \mathrm{~K}$ structure may be strong candidates for the development of broad-spectrum inhibitors of coronavirus replication. With the $3 \mathrm{~K}$ inhibitor showing efficacy to the $\mathrm{M}^{\text {Pro }}$ of SARS-CoV and MERS-CoV, there is a hope that it may have a similar efficacy towards SARS-CoV-2. This study demonstrates that neuraminidase inhibitors are capable of interacting with the active site of the SARS$\mathrm{CoV}-2 \mathrm{M}^{\text {Pro }}$, but further studies are necessary to discover an inhibitor capable of stopping viral replication in vitro.

\section{Peptidomimetic Inbibitors (11 a and 11b)}

Peptidomimetics are a class of inhibitors designed to mimic the structure of peptides. Interest for these molecules is growing because they demonstrate high potency, strong target selectivity, and a prolonged duration of activity when compared to natural peptides. ${ }^{59}$ Peptidomimetic inhibitor studies in SARS-CoV and SARS-CoV-2 show efficacy in targeting and inhibiting the viral $\mathrm{M}^{\text {Pro }}$, thus making them a promising strategy of inhibition. ${ }^{56,61} \mathrm{Wong}$, et al., examined the effects of 5 different inhibitors on SARS-CoV M $\mathrm{M}^{\text {Pro }}$ with $\mathrm{IC}_{50}$ values between 5 and $52 \mu \mathrm{M}$. The most promising formed a covalent bond with Cys 145 , completely preventing enzymatic proteolysis. ${ }^{56}$ In a more recent study by Chuck, et al., peptidomimetic inhibitors showed the ability to inhibit the $\mathrm{M}^{\text {Pro }}$ of SARS-CoV. ${ }^{67}$ Four inhibitors were tested and demonstrated $\mathrm{IC}_{50}$ values ranging from 4.6 to $49 \mu \mathrm{M} .{ }^{67}$ The significant range in $\mathrm{IC}_{50}$ is a result of minor alterations of functional groups on each moiety.

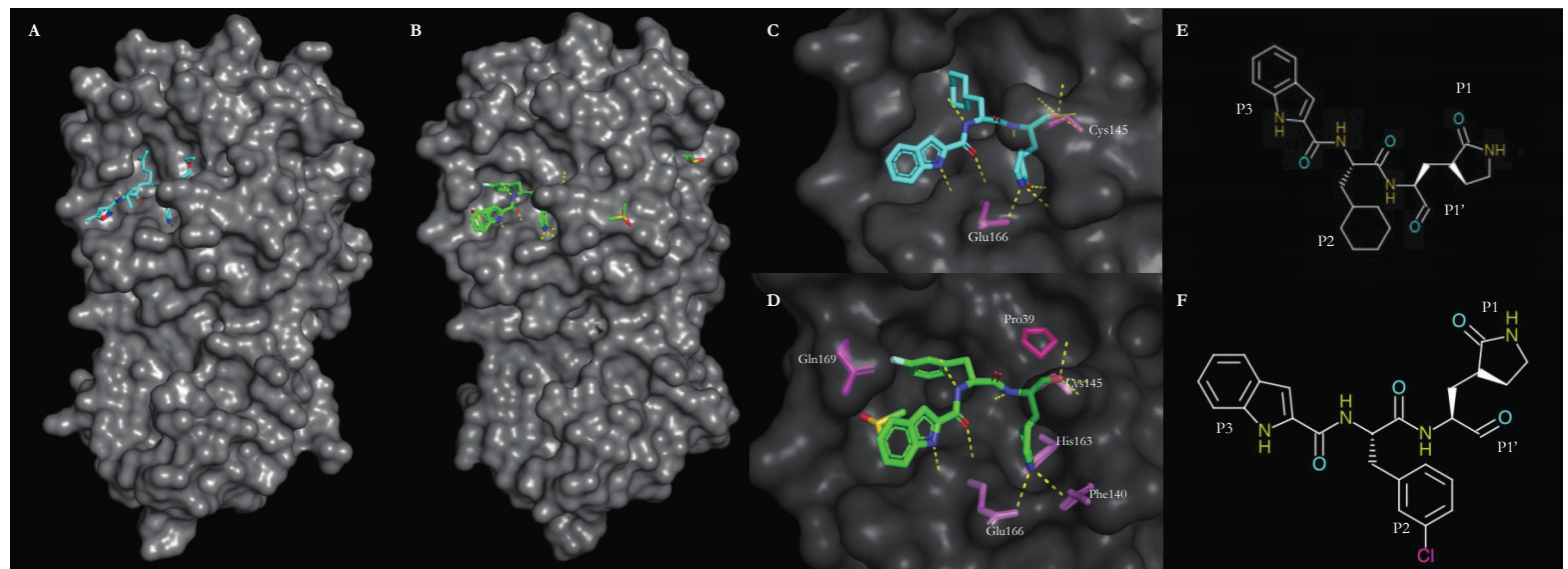

Figure 7. A. The $\mathrm{M}^{\text {Pro }}$ of SARS-CoV-2 with compound 11a (PDB: 6LZE). ${ }^{68} \mathrm{~B}$. The $\mathrm{M}^{\text {Pro }}$ of SARS-CoV-2 with compound $11 \mathrm{~b}$ interacting with the active site (PDB: 6M0K) ${ }^{68} \mathrm{C}$, D. Polar interactions between the protease and inhibitor $11 \mathrm{a}$ or $11 \mathrm{~b}$, respectively, are shown by dashed yellow lines. E. The chemical structure of compound 11a. F. The chemical structure of compound 11b. This figure was prepared with PyMOL. ${ }^{36}$

Dai, et al., investigated the efficacy of peptidomimetic aldehyde-based inhibitors, shown in Figure 7, against the SARS-CoV-2 $\mathrm{M}^{\text {Pro }}{ }^{61}$ An antiviral activity assay was performed in Vero E6 cells that had been infected with SARS-CoV-2. Synthesized compounds $11 \mathrm{a}$ and $11 \mathrm{~b}$ showed robust SARS-CoV-2 inhibitory activity. Compound $11 \mathrm{a}$ differs from $11 \mathrm{~b}$ in the $\mathrm{P}_{2}$ site; $11 \mathrm{a}$ contains a cyclohexyl group whereas $11 \mathrm{~b}$ has an aryl group. Compounds $11 \mathrm{a}$ and $11 \mathrm{~b}$ potently inhibit SARS-CoV-2 $\mathrm{M}^{\text {Pro }}$ with $\mathrm{IC}_{50}$ values of $0.053 \pm 0.005 \mu \mathrm{M}$ and $0.040 \pm 0.002 \mu \mathrm{M}$ respectively, Table 1 . The low $\mathrm{IC}_{50}$ values are a result of strong interactions that occur between the inhibitors and the $\mathrm{M}^{\text {Pro }}$. Compound $11 \mathrm{a}$ and $11 \mathrm{~b}$ predominantly interact with amino acids in the $\mathrm{S}_{1}$ and $\mathrm{S}_{1}$ subsites. Interactions in the $\mathrm{S}_{1}$ ' subsite include a covalent bond formed between the aldehyde at the $\mathrm{P}_{1}$ site of $11 \mathrm{a}$ and $\mathrm{Cys}_{145}$ as well as hydrogen bond formed with the backbone of Cys145 and Gly143. In the $\mathrm{S}_{1}$ pocket of the M ${ }^{\text {Pro }}$ the (S)-y-Lactam ring at the $\mathrm{P}_{1}$ site of 11a forms hydrogen bonds with the side chains His163 and Glu166, and the main chain of Phe140. The $\mathrm{P}_{2}$ site of 11a forms hydrophobic interactions with the side chains of Met49, Tyr54, Met165 and Asp187 in the $\mathrm{S}_{2}$ pocket of the $\mathrm{M}^{\text {Pro }}$. The $\mathrm{S}_{4}$ subsite interacts with the $\mathrm{P}_{3}$ of 11 a by hydrophobic interactions between Pro168 and Gln189. Together, the interactions between $11 \mathrm{a}$ and the $\mathrm{M}^{\text {Pro }}$ form a stable interaction which inhibits viral activity. Similarly, $11 \mathrm{~b}$ exhibits the same interactions in the $S_{1}, S_{1}$, and $\mathrm{S}_{4}$ subsites of the $\mathrm{M}^{\text {Pro }}$, but the aryl group at the $\mathrm{P}_{2}$ site of $11 \mathrm{~b}$ results in different interactions with the $\mathrm{S}_{2}$ subsite. Specifically, $11 \mathrm{~b}$ forms hydrophobic interactions in the $\mathrm{S}_{2}$ subsite with His41, Met49, Met165, and Val186. Additionally, a hydrogen bond 
forms between the side chain of $G \ln 189$ and $11 \mathrm{~b}$ to stabilize the inhibitor in the active site. ${ }^{61}$ Both of these compounds form a covalent bond with Cys145, which is essential for antiviral activity. However, neither of these inhibitors form a hydrogen bond with His41, a mechanism commonly found in several other successful inhibitors. Strong interactions between compounds 11a and $11 \mathrm{~b}$ with the active site pocket of $\mathrm{M}^{\text {Pro }}$ suggest these compounds are promising candidates in preventing viral replication, warranting further research.

\section{Alpha-Ketoamide Inbibitor (13b)}

Another class of inhibitors, $\alpha$-ketoamide inhibitors, show great potential in targeting the $\mathrm{M}^{\text {Pro }}$ of coronaviruses. Zhang, et al., reported the design of various modified $\alpha$-ketoamide inhibitors of the $\mathrm{M}^{\text {Pro }}$ of beta coronaviruses, alpha coronavirus, and $3 \mathrm{C}$ proteases of enteroviruses. ${ }^{65}$ Previously, the group had developed an $\alpha$-ketoamide inhibitor, $11 \mathrm{r}$, with a low EC50 against the SARS-CoV M ${ }^{\text {Pro }}$ and an $\mathrm{EC}_{50}$ value of $400 \mathrm{pM}$ against MERS-CoV. ${ }^{64}$ With the goal of preventing SARS-CoV-2 MPro from cleaving Nsps, the group modified the $\alpha$-ketoamide inhibitor and studied its efficacy in silico and in vitro. The designed $\alpha$-ketoamide inhibitor (13b) includes a pyridine ring (Figure 8) that sterically clashes with Gln189. ${ }^{64}$ However, previous computational studies indicate Gln189 is flexible, and may allow for proper binding in vitro. Computational docking studies provide a suggested mechanism of interaction between $13 \mathrm{~b}$ and the $\mathrm{M}^{\text {Pro }}$ of SARS-CoV-2. A nucleophilic attack of the catalytic Cys145 onto the $\alpha$ ketoamide 13b inhibitor initiates binding, forming a thiohemiacetal in a reversible reaction. The $\alpha$-ketoamide inhibitor $13 \mathrm{~b}$ structure then interacts with the catalytic dyad of the cysteine protease, which behaves as an "oxyanion hole" during catalysis, via hydrogen bonds. ${ }^{65}$ This interaction prevents catalysis. Zhang, L., et al., identified some of the necessary interactions that $13 \mathrm{~b}$ has with the $\mathrm{M}^{\text {Pro }}$ of SARS-CoV-2 to prevent viral replication. A subsequent study by Gimeno, et al., completed the understanding of these interactions between $13 \mathrm{~b}$ and the $\mathrm{M}^{\text {Pro }}$.

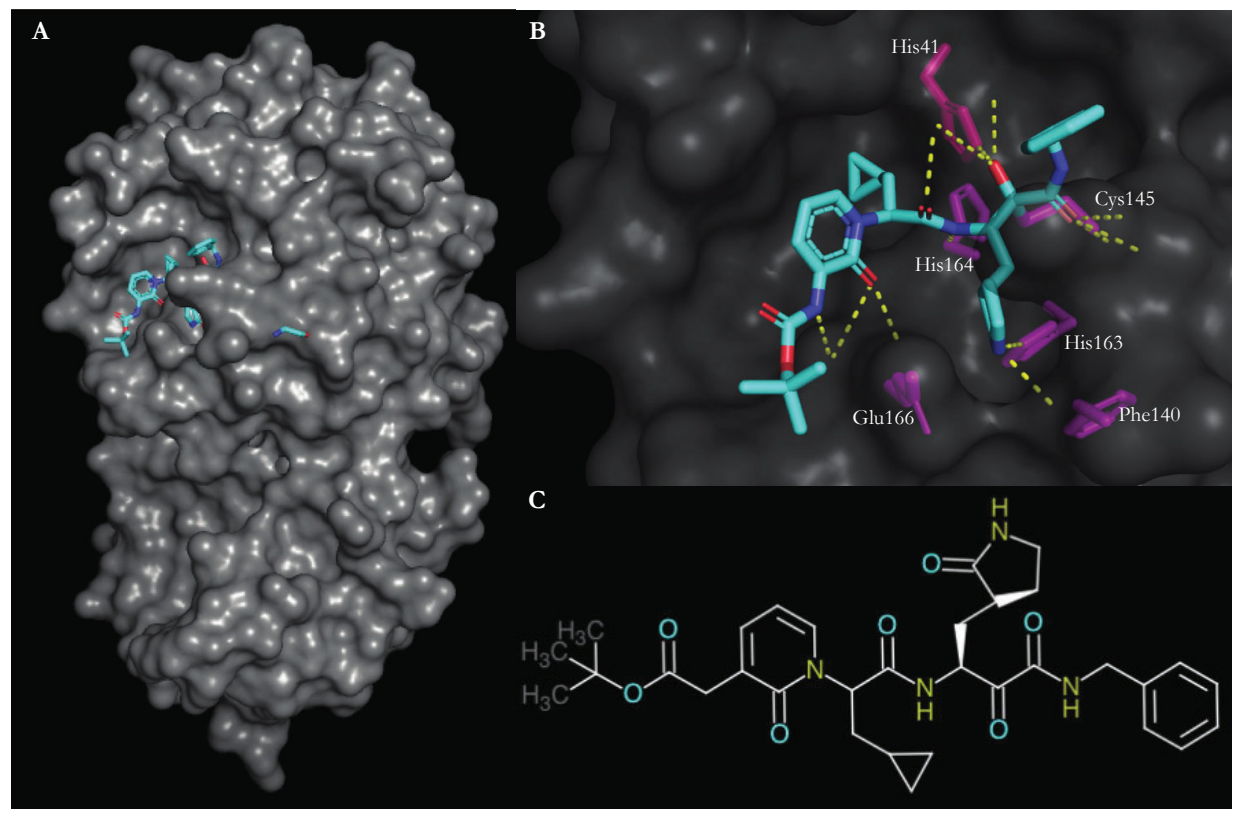

Figure 8. A. Compound 13b bound to the $\mathrm{M}^{\text {Pro }}$ of SARS-CoV-2 (PDB: $\left.6 \mathrm{Y} 2 \mathrm{G}\right) \cdot{ }^{65} \mathrm{~B}$. The active site of the $\mathrm{M}^{\mathrm{Pro}}$ and the polar interactions it has with compound 13b, as shown by dashed yellow lines. C. The chemical structure of inhibitor 13b. This figure was made through the use of PyMOL. ${ }^{36}$

Gimeno, et al., found 13b forms hydrogen bonds and has hydrophobic interactions with other amino acids in the active site, as seen in Table 2. Some of the most important observed interactions include a hydrogen bond with the carbonyl oxygen of His164 that acts as an anchoring point as shown in Figure 8b. The hydrophobic interactions that occur in the $\mathrm{S}_{4}$ and $\mathrm{S}_{2}$ subsites act as a "hydrophobic grip" on the inhibitor and increase binding affinity. In the $\mathrm{S}_{1}$ subsite, $13 \mathrm{~b}$ hydrogen bonds with Glu166, the backbone of Phe140 and the side chain of His163. ${ }^{43}$ Given that $13 \mathrm{~b}$ forms a covalent bond with Cys145 and has other strong interactions with the $\mathrm{M}^{\text {Pro }}$, it is a strong candidate for a broad-spectrum inhibitor of coronaviruses. ${ }^{43}$ Though this promise has been revealed by computational analysis, cellular assays are necessary to provide further insight regarding the efficacy of $13 \mathrm{~b}$ as a coronavirus inhibitor. 
Aldebyde Prodrug (GC-376)

GC-376 is an aldehyde prodrug and demonstrates strong affinity for the M ${ }^{\text {Pro }}$ of SARS-CoV-2.63 This is accomplished by GC-376 structurally mimicking the Nsps that the $\mathrm{M}^{\text {Pro }}$ cleaves. X-ray crystallography has revealed the binding interactions between GC376 and the M $\mathrm{M}^{\text {Pro }}$ of SARS-CoV-2 (Figure 9). ${ }^{63}$ This inhibitor is unique due to its two different conformations in the active site where the oxyanion hole is located. In the $\mathrm{S}$ conformation the oxyanion hole is occupied by the thioacetal hydroxide. However, in the $\mathrm{R}$ conformation the thioacetal hydroxide sticks out and forms a hydrogen bond with His41. Like the $\alpha$-ketoamide inhibitors, a covalent bond forms between GC-376 and Cys145, locking the inhibitor into the active site. GC-376 also forms a number of hydrogen bonds and has hydrophobic interactions with the $S_{2}$ and $S_{4}$ subsites of the active site. The $\gamma$-lactam ring occupies the $S_{1}$ subsite and forms hydrogen bonds with the side chains of His163 and Glu166 as well as the main chain of Phe140. In the $\mathrm{S}_{1}$ subsite, GC-376 forms a hydrogen bond with His41 or has a hydrophobic interaction with this amino acid, due to the two different conformations mentioned above. The $\mathrm{S}_{2}$ subsite of the $\mathrm{M}^{\text {Pro }}$ is occupied by an isobutyl group that forms hydrophobic interactions with Met49 and Met146. Other hydrophobic interactions occur in the $\mathrm{S}_{4}$ subsite which is occupied by the phenylmethyl ester of GC-376. In addition to structural analysis of binding, the GC-376 inhibitor has also been studied in cell cultures to determine the efficiency of antiviral activity, demonstrating an $\mathrm{IC}_{50}$ value of $0.03 \mu \mathrm{M} .{ }^{63}$

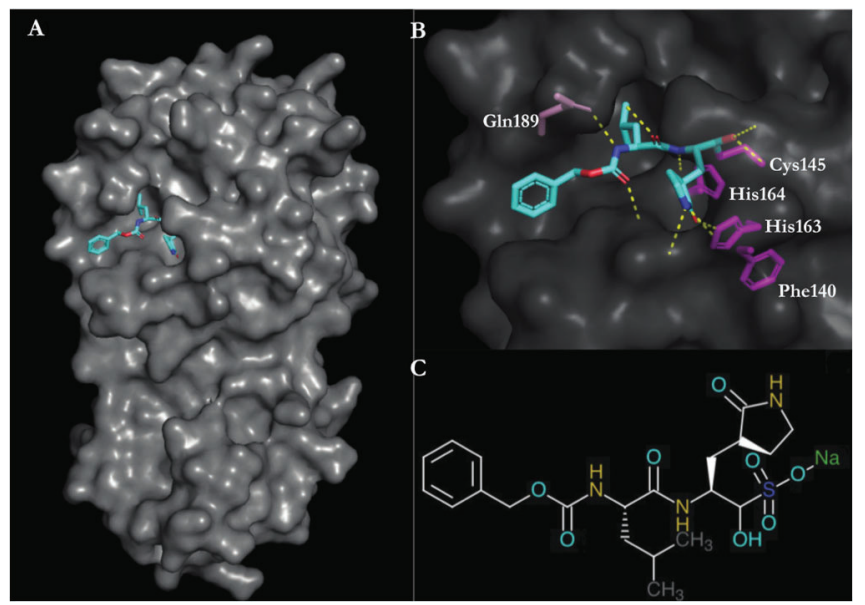

Figure 9. A. The SARS-CoV-2 MPro in complex with the inhibitor GC-376 (PDB: 6WTT). ${ }^{63}$ B. The active site of the MPro with GC-376 and polar interactions between them, as shown by dashed yellow lines. C. The chemical structure of GC-376. This image was made with the use of PyMOL. ${ }^{36}$

Phosphate Prodrug PF-07304814

PF-07304814 (Figure 10) is a highly soluble, phosphate prodrug capable of inhibiting 12 different coronavirus strains across the $\alpha, \beta$, and $\gamma$ coronavirus families. ${ }^{62}$ Alkaline phosphatase enzymes rapidly cleave the phosphate molecule, metabolizing it into the active moiety, PF-00835231.62 Analysis by Boras, B., et al,. shows PF-07304814 strongly inhibits the MPro of SARS-CoV. The inhibitor forms an irreversible covalent bond with Cys145 at the active site of the $\mathrm{M}^{\text {Pro }}$. Binding of this drug induces a melting temperature shift of $14.6^{\circ} \mathrm{C}$, indicating tight binding of the molecule and protein. PF-0083521 demonstrates a low affinity for human proteases and, therefore, shows strong selectivity towards coronavirus $\mathrm{M}^{\text {Pro }}$ s. Nonhuman-primate studies demonstrate that PF-07304814 has strong preclinical safety features and robust antiviral activity. A limitation of this drug is the requirement for intravenous delivery, which complicates delivery of the drug beyond the clinic. The cellular assays alone provide robust support for the potential of a novel $\mathrm{M}^{\text {Pro }}$ inhibitor capable of broad-spectrum coronavirus activity. ${ }^{62}$ Structural analysis of inhibitor interactions with the binding site provides further insight.

A structural inventory of protein-drug interactions confirms that PF-00835231 forms a covalent bond with Cys145 (Figure 10B). It also forms hydrogen bonds with the side chains of Phe140, His163, and Glu166. Additional hydrogen bonds, indicated by yellow dashes, in Figure 10B are formed with the backbone moieties of Met165, Cys145, and His164. From our analysis, we were able to determine polar interactions and hypothesize the hydrophobic interactions. A comparison of hydrophobic interactions of other inhibitors determined how the $\mathrm{M}^{\text {Pro }}$ may interact with the hydrophobic areas of the prodrug. We identified hydrophobic contacts with the side chains of His41, Met49, Tyr54, and Pro168, as well as with the aliphatic portion of the Asp187 side chain. These hydrophobic interactions increase the attraction between the inhibitor and the active site of the $\mathrm{M}^{\text {Pro }}$. It is important to note that an inventory based on structure will need to be confirmed by other, more rigorous, analysis like in silico docking. 


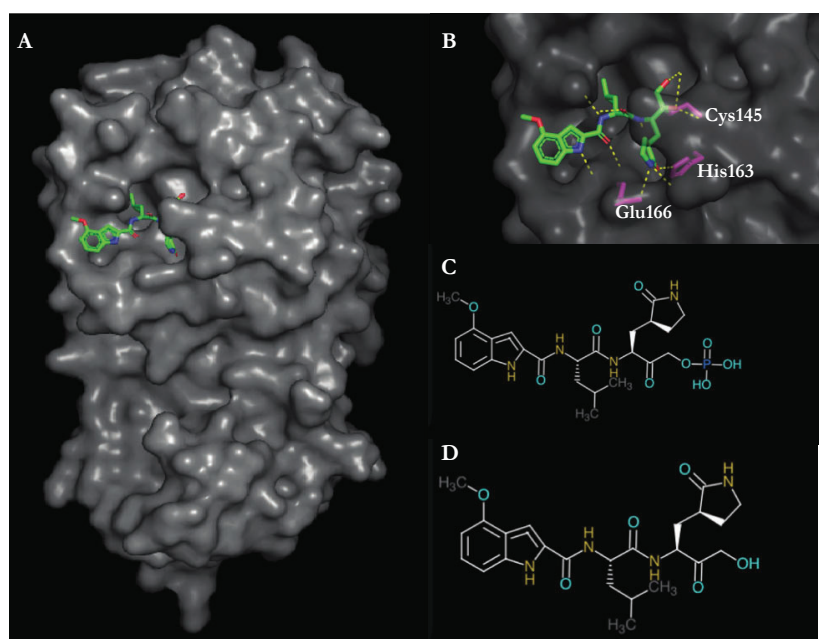

Figure 10. A. SARS-CoV-2 M ${ }^{\text {Pro }}$ with the phosphate prodrug at the active site (PDB: $\left.6 \mathrm{XHM}\right){ }^{62} \mathrm{~B}$. A zoomed-in view of the active site with the phosphate prodrug and the polar interactions between them, showed by the dashed yellow lines. C. Chemical structure of PF-07304814, the prodrug. D. Chemical structure of PF-00835231, the active form. This figure was made through the use of PyMOL. ${ }^{36}$

\section{CONCLUSION}

The highly pathogenic coronavirus outbreaks of the past two decades show similarity in structure and function of the M ${ }^{\text {Pro }}$. SARS$\mathrm{CoV}$ and SARS-CoV-2 share the most similarities, and MERS-CoV is less similar. However, the active site of the main proteases demonstrates a high degree of structural conservation across all coronavirus lines, specifically the Cys145-His41 catalytic dyad and GSCGS recognition site. Spanning domains I and II as well as the N-finger, the active site holds relevance as a center point for therapeutic targeting and rational drug design across the three viruses. This review catalogs four groups of novel inhibitors that target the main protease of coronaviruses. The $3 \mathrm{k}$ inhibitor, a neuraminidase inhibitor, shows efficacy in inhibiting the $\mathrm{M}^{\mathrm{Pro}} \mathrm{s}$ of SARS-CoV and MERS-CoV.44 3k interacts with the active site via a combination of hydrogen bonds and hydrophobic interactions, but this compound does not form a covalent bond with the Cys145, a property of other compounds known to improve inhibition. ${ }^{44}$ However, in silico models of this drug in the active site provides evidence that the $\mathrm{S}_{4}$ pocket of the $\mathrm{M}^{\text {Pro }}$ in MERS-CoV is smaller than the $\mathrm{S}_{4}$ pocket of the M $\mathrm{M}^{\text {Pro }}$ in the SARS-CoV. ${ }^{44}$ This understanding allows for a simple modification in the inhibitor to better fit into the smaller hydrophobic pocket. Another class of inhibitors, peptidomimetic inhibitors, readily allow for chemical modifications to better fit the protease's binding pocket. ${ }^{56,61}$ The two most promising candidates in this class of inhibitors are $11 \mathrm{a}$ and $11 \mathrm{~b}$, which covalently bind to the $\mathrm{M}^{\text {Pro }}$ of SARS-CoV-2. These inhibitors also form hydrogen bonds and have hydrophobic interactions with the $\mathrm{M}^{\text {Pro }}$. Their low $\mathrm{IC}_{50}$ values show that they are promising inhibitors for further study. Compound $13 \mathrm{~b}$ is a modified $\alpha$-ketoamide inhibitor capable of covalently binding Cys145 and has a low $\mathrm{IC}_{50}$ value. ${ }^{64}$ All four inhibitors show high efficacy either in silico or in vitro, yet all four lack animal studies to validate their efficacy in vivo. An aldehyde prodrug, GC376, is another promising novel coronavirus inhibitor because it has a very low IC50 value (0.03 uM) and forms a covalent bond with Cys145, blocking viral replication. ${ }^{63}$ The phosphate prodrug PF-07304814 is a novel compound shown to inhibit the main protease of coronaviruses and decrease viral load in nonhuman primates. ${ }^{62}$ Importantly, in vitro assays show the prodrug's ability to inhibit the main protease of a dozen different coronaviruses, showing the potential for broad spectrum therapy against coronaviruses. Taken together, the information reviewed in this article suggests inhibitors designed for one coronavirus protease are likely to be effective against $\mathrm{M}^{\text {Pro }}$ of other coronaviruses. Ideally, modification of these inhibitors will produce drugs with great efficacy. Regardless of the challenges, the potential for broad-spectrum, coronavirus therapeutic design appears possible and within reach. The implications of universal inhibitor design offer hope for clinicians during both today's coronavirus pandemic, and any future outbreaks.

\section{REFERENCES}

1. WHO | Cumulative Number of Reported Probable Cases of SARS. (2015). WHO.

2. WHO Coronavirus Disease (COVID-19) Dashboard | WHO Coronavirus Disease (COVID-19) Dashboard. (n.d.). Retrieved January 29, 2021, from https:/ / covid19.who.int/

3. WHO EMRO | MERS outbreaks | MERS-CoV| Health topics. (n.d.). Retrieved January 29, 2021, from http:// www.emro.who.int/ health-topics/mers-cov/ mers-outbreaks.html

4. Ye, Z.-W., Yuan, S., Yuen, K.-S., Fung, S.-Y., Chan, C.-P., \& Jin, D.-Y. (2020). Zoonotic origins of human coronaviruses. International Journal of Biological Sciences, 16(10), 1686-1697. https:/ / doi.org/ 10.7150/ijbs.45472

5. Drexler, J. F., Corman, V. M., \& Drosten, C. (2014). Ecology, evolution and classification of bat coronaviruses in the aftermath of SARS. In Antiviral Research (Vol. 101, Issue 1, pp. 45-56). https:// doi.org/10.1016/j.antiviral.2013.10.013

6. LeDuc, J. W., \& Barry, M. A. (2004). SARS, the First Pandemic of the 21st Century. In Emerging Infectious Diseases (Vol. 10, 
Issue 11, p. e26). https://doi.org/10.3201/eid1011.040797_02

7. Al-Osail, A. M., \& Al-Wazzah, M. J. (2017). The history and epidemiology of Middle East respiratory syndrome corona virus. In Multidisciplinary Respiratory Medicine (Vol. 12, Issue 1). BioMed Central Ltd. bttps:/ / doi.org/10.1186/s40248-017-0101-8

8. WHO | Update 49 - SARS case fatality ratio, incubation period. (2015). WHO.

9. Donnelly, C. A., Malik, M. R., Elkholy, A., Cauchemez, S., \& Van Kerkhove, M. D. (2019). Worldwide Reduction in MERS Cases and Deaths since 2016. In Emerging infectious diseases (Vol. 25, Issue 9, pp. 1758-1760). bttps:// doi.org/ 10.3201/ eid2509.190143

10. Dong, E., Du, H., \& Gardner, L. (2020). An interactive web-based dashboard to track COVID-19 in real time. In The Lancet Infectious Diseases (Vol. 20, Issue 5, pp. 533-534). Lancet Publishing Group. https:/ / doi.org/ 10.1016/S1473-3099(20)30120-1

11. Jaiswal, N. K., \& Saxena, S. K. (2020). Classical Coronaviruses. In Coronavirus Disease 2019 (COVID-19): Epidemiology, Pathogenesis, Diagnosis, and Therapeutics (pp. 141-150). https:// doi.org/10.1007/978-981-15-4814-7_12

12. Tang, X. C., Zhang, J. X., Zhang, S. Y., Wang, P., Fan, X. H., Li, L. F., Li, G., Dong, B. Q., Liu, W., Cheung, C. L., Xu, K. M., Song, W. J., Vijaykrishna, D., Poon, L. L. M., Peiris, J. S. M., Smith, G. J. D., Chen, H., \& Guan, Y. (2006). Prevalence and Genetic Diversity of Coronaviruses in Bats from China. Journal of Virology, 80(15), 7481-7490. bttps:/ / doi.org/ 10.1128/jvi.00697-06

13. Kim, Y., Cho, Y., Kim, D., Yang, J., Kim, H., Park, S., Han, Y. W., Yun, M., Lee, H. S., Kim, A., Heo, D. R., Kim, J. A., Kim, S. J., Jung, H., Kim, N., Yoon, S., Nam, J., Kang, H. J., Cheong, H., ... Kim, S. S. (2015). Complete Genome Sequence of Middle East Respiratory Syndrome. 3(4), 3-4. https:/ / doi.org/10.1128/genomeA.00787-15.Copyright

14. Marco, A., Steven, J. M., Caroline, R., \& Robert, A. (2003). The Genome sequence of the SARS-associated coronavirus .

15. Khailany, R. A., Safdar, M., \& Ozaslan, M. (2020). Genomic characterization of a novel SARS-CoV-2. Gene Reports, 19. bttps:// doi.org/10.1016/j.genrep.2020.100682

16. THE CORONAVIRUS REPLICASE: INSIGHTS INTO A SOPHISTICATED ENZYME MACHINERY. (n.d.).

17. Woo, P. C. Y., Huang, Y., Lau, S. K. P., \& Yuen, K. Y. (2010). Coronavirus genomics and bioinformatics analysis. In Viruses (Vol. 2, Issue 8, pp. 1805-1820). MDPI AG. https://doi.org/10.3390/v2081803

18. Neuman, B. W., Chamberlain, P., Bowden, F., \& Joseph, J. (2014). Atlas of coronavirus replicase structure. Virus Research, 194, 49-66. https:/ / doi.org/10.1016/j.virusres.2013.12.004

19. Báez-Santos, Y. M., St. John, S. E., \& Mesecar, A. D. (2015). The SARS-coronavirus papain-like protease: Structure, function and inhibition by designed antiviral compounds. In Antiviral Research (Vol. 115, pp. 21-38). Elsevier B.V. bttps://doi.org/10.1016/j.antiviral.2014.12.015

20. Kamitani, W., Huang, C., Narayanan, K., Lokugamage, K. G., \& Makino, S. (2009). A two-pronged strategy to suppress host protein synthesis by SARS coronavirus Nsp1 protein. Nature Structural and Molecular Biology, 16(11), 1134-1140. https://doi.org/10.1038/nsmb.1680

21. Zhai, Y., Sun, F., Li, X., Pang, H., Xu, X., Bartlam, M., \& Rao, Z. (2005). Insights into SARS-CoV transcription and replication from the structure of the nsp7-nsp8 hexadecamer. Nature Structural and Molecular Biology, 12(11), 980-986. bttps:/ / doi.org/ 10.1038/nsmb999

22. Bartlam, M., Yang, H., \& Rao, Z. (2005). Structural insights into SARS coronavirus proteins. In Current Opinion in Structural Biology (Vol. 15, Issue 6, pp. 664-672). https:// doi.org/10.1016/j.sbi.2005.10.004

23. Sutton, G., Fry, E., Carter, L., Sainsbury, S., Walter, T., Nettleship, J., Berrow, N., Owens, R., Gilbert, R., Davidson, A., Siddell, S., Poon, L. L. M., Diprose, J., Alderton, D., Walsh, M., Grimes, J. M., \& Stuart, D. I. (2004). The nsp9 Replicase Protein of SARS-Coronavirus, Structure and Functional Insights. Structure, 12(2), 341-353. https:// doi.org/10.1016/j.str.2004.01.016

24. Egloff, M.-P., Ferron, F., Rie Campanacci, V., Longhi, S., Rancurel, C., Lè Ne Dutartre, H., Snijder, E. J., Gorbalenya, A. E., Cambillau, C., \& Canard, B. (2004). The severe acute respiratory syndrome-coronavirus replicative protein nsp9 is a single-stranded RNAbinding subunit unique in the RNA virus world. www.pnas.orgcgidoi10.1073pnas.0307877101

25. Bouvet, M., Debarnot, C., Imbert, I., Selisko, B., Snijder, E. J., Canard, B., \& Decroly, E. (2010). In vitro reconstitution of sars-coronavirus mRNA cap methylation. PLoS Pathogens, 6(4), 1-13. https:// doi.org/10.1371/journal.ppat.1000863

26. van Dinten, L. C., van Tol, H., Gorbalenya, A. E., \& Snijder, E. J. (2000). The Predicted Metal-Binding Region of the Arterivirus Helicase Protein Is Involved in Subgenomic mRNA Synthesis, Genome Replication, and Virion Biogenesis. Journal of Virology, 74(11), 5213-5223. https:// doi.org/10.1128/jvi.74.11.5213-5223.2000

27. Tanner, J. A., Watt, R. M., Chai, Y. B., Lu, L. Y., Lin, M. C., Peiris, J. S. M., Poon, L. L. M., Kung, H. F., \& Huang, J. D. (2003). The severe acute respiratory syndrome (SARS) coronavirus NTPasefhelicase belongs to a distinct class of $5^{\prime}$ to $3^{\prime}$ viral helicases. Journal of Biological Chemistry, 278(41), 39578-39582. https:/ / doi.org/ 10.1074/jbc.C300328200

28. Ivanov, K. A., Thiel, V., Dobbe, J. C., van der Meer, Y., Snijder, E. J., \& Ziebuhr, J. (2004). Multiple Enzymatic Activities Associated with Severe Acute Respiratory Syndrome Coronavirus Helicase. Journal of Virology, 78(11), 5619-5632. bttps:// doi.org/10.1128/jvi.78.11.5619-5632.2004

29. Minskaia, E., Hertzig, T., Gorbalenya, A. E., Campanacci, V., Cambillau, C., Canard, B., \& Ziebuhr, J. (2006). Discovery of an RNA virus $3^{\prime} \rightarrow 5$ ' exoribonuclease that is critically involved in coronavirus RNA synthesis. Proceedings of the National Academy of 
Sciences of the United States of America, 103(13), 5108-5113. https:/ / doi.org/10.1073/pnas.0508200103

30. Rathnayake, A. D., Zheng, J., Kim, Y., Perera, K. D., Mackin, S., Meyerholz, D. K., Kashipathy, M. M., Battaile, K. P., Lovell, S., Perlman, S., Groutas, W. C., \& Chang, K.-O. (2020). 3C-like protease inhibitors block coronavirus replication in vitro and improve survival in MERS-CoV-infected mice. Science Translational Medicine, 5332(August), eabc5332. bttps:/ / doi.org/10.1126/ scitranslmed.abc5332

31. Jin, Z., Zhao, Y., Sun, Y., Zhang, B., Wang, H., Wu, Y., Zhu, Y., Zhu, C., Hu, T., Du, X., Duan, Y., Yu, J., Yang, X., Yang, X., Yang, K., Liu, X., Guddat, L. W., Xiao, G., Zhang, L., ... Rao, Z. (2020). Structural basis for the inhibition of SARS-CoV-2 main protease by antineoplastic drug carmofur. Nature Structural and Molecular Biology, 27(6), 529-532. bttps:/ / doi.org/10.1038/s41594-020-0440-6

32. Casalino, L., Gaieb, Z., Goldsmith, J. A., Hjorth, C. K., Dommer, A. C., Harbison, A. M., Fogarty, C. A., Barros, E. P., Taylor, B. C., McLellan, J. S., Fadda, E., \& Amaro, R. E. (2020). Beyond Shielding: The Roles of Glycans in the SARS-CoV-2 Spike Protein. ACS Central Science. https:/ / doi.org/10.1021/acscentsci.0c01056

33. Yang, H., Yang, M., Ding, Y., Liu, Y., Lou, Z., Zhou, Z., Sun, L., Mo, L., Ye, S., Pang, H., Gao, G. F., Anand, K., Bartlam, M., Hilgenfeld, R., \& Rao, Z. (2003). The crystal structures of severe acute respiratory syndrome virus main protease and its complex with an inhibitor. Proceedings of the National Academy of Sciences of the United States of America, 100(23), 13190-13195. https://doi.org/ 10.1073/pnas.1835675100

34. Needle, D., Lountos, G. T., \& Waugh, D. S. (2015). Structures of the Middle East respiratory syndrome coronavirus 3C-like protease reveal insights into substrate specificity. Acta Crystallographica Section D: Biological Crystallography, 71, $1102-1111$. https:// doi.org/10.1107/S1399004715003521

35. RCSB PDB - 6YB7: SARS-CoV-2 main protease with unliganded active site (2019-nCoV, coronavirus disease 2019, COVID-19). (n.d.).

36. Schrodinger LLC. (2015). The PyMOL Molecular Graphics System, Version 1.8.

37. Kaur, N., Singh, R., Dar, Z., Bijarnia, R. K., Dhingra, N., \& Kaur, T. (2020). Genetic comparison among various coronavirus strains for the identification of potential vaccine targets of SARS-CoV2. Infection, Genetics and Evolution, 104490.

https:// doi.org/10.1016/j.meegid.2020.104490

38. Tahir ul Qamar, M., Alqahtani, S. M., Alamri, M. A., \& Chen, L. L. (2020). Structural basis of SARS-CoV-2 3CLpro and antiCOVID-19 drug discovery from medicinal plants. Journal of Pharmaceutical Analysis, 10(4), 313-319. https:// doi.org/ 10.1016/j.jpha.2020.03.009

39. Wang, H., He, S., Deng, W., Zhang, Y., Li, G., Sun, J., Zhao, W., Guo, Y., Yin, Z., Li, D., \& Shang, L. (2020). Comprehensive Insights into the Catalytic Mechanism of Middle East Respiratory Syndrome 3C-Like Protease and Severe Acute Respiratory Syndrome 3C-Like Protease. ACS Catalysis, 10(10), 5871-5890. https:/ / doi.org/10.1021 / acscatal.0c00110

40. Zhong, N., Zhang, S., Zou, P., Chen, J., Kang, X., Li, Z., Liang, C., Jin, C., \& Xia, B. (2008). Without Its N-Finger, the Main Protease of Severe Acute Respiratory Syndrome Coronavirus Can Form a Novel Dimer through Its C-Terminal Domain. Journal of Virology, 82(9), 4227 LP - 4234. https:/ / doi.org/10.1128/JV1.02612-07

41. Huang, C., Wei, P., Fan, K., Liu, Y., \& Lai, L. (2004). 3C-like Proteinase from SARS Coronavirus Catalyzes Substrate Hydrolysis by a General Base Mechanism. Biochemistry, 43(15), 4568-4574. https://doi.org/10.1021/bi036022q

42. Chang, G.-G. (2009). Quaternary Structure of the SARS Coronavirus Main Protease. Molecular Biology of the SARS-Coronavirus, 115-128. https:// doi.org/10.1007/978-3-642-03683-5_8

43. Gimeno, A., Mestres-Truyol, J., Ojeda-Montes, M. J., Macip, G., Saldivar-Espinoza, B., Cereto-Massagué, A., Pujadas, G., \& Garcia-Vallvé, S. (2020). Prediction of novel inhibitors of the main protease (M-pro) of SARS-CoV-2 through consensus docking and drug reposition. International Journal of Molecular Sciences, 21(11). bttps:/ / doi.org/ 10.3390/ijms21113793

44. Kumar, V., Tan, K. P., Wang, Y. M., Lin, S. W., \& Liang, P. H. (2016). Identification, synthesis and evaluation of SARS-CoV and MERS-CoV 3C-like protease inhibitors. Bioorganic and Medicinal Chemistry, 24(13), 3035-3042. bttps:// doi.org/10.1016/j.bmc.2016.05.013

45. Verschueren, K. H. G., Pumpor, K., Anemüller, S., Chen, S., Mesters, J. R., \& Hilgenfeld, R. (2008). A structural view of the inactivation of the SARS coronavirus main proteinase by benzotriazole esters. Chemistry \& Biology, 15(6), 597-606. https:/ / doi.org/ 10.1016/j.chembiol.2008.04.011

46. Fintelman-Rodrigues, N., Sacramento, C., Lima, C. R., da Silva, F. S., Ferreira, A., Mattos, M., de Freitas, C., Soares, V. C., Gomes Dias, S. da S., Temerozo, J., Miranda, M., Matos, A., Bozza, F., Carels, N., Alves, C. R., Siqueira, M., Bozza, P., \& Souza, T. M. (2020). Atazanavir inbibits SARS-CoV-2 replication and pro-inflammatory cytokine production. bttps:// doi.org/10.1101/2020.04.04.020925

47. De Meyer, S., Bojkova, D., Cinatl, J., Van Damme, E., Buyck, C., Van Loock, M., Woodfall, B., \& Ciesek, S. (2020). Lack of antiviral activity of darunavir against SARS-CoV-2. International Journal of Infectious Diseases, 97, 7-10. bttps:// doi.org/ 10.1016/j.ijid.2020.05.085

48. Jin, Z., Du, X., Xu, Y., Deng, Y., Liu, M., Zhao, Y., Zhang, B., Li, X., Zhang, L., Peng, C., Duan, Y., Yu, J., Wang, L., Yang, K., Liu, F., Jiang, R., Yang, X., You, T., Liu, X., ... Yang, H. (2020). Structure of Mpro from SARS-CoV-2 and discovery of its inhibitors. Nature, 582(7811), 289-293. https:// doi.org/10.1038/s41586-020-2223-y

49. Sies, H., \& Parnham, M. J. (2020). Potential therapeutic use of ebselen for COVID-19 and other respiratory viral infections. 
Free Radical Biology and Medicine, 156(June), 107-112. https:/ / doi.org/ 10.1016/j.freeradbiomed.2020.06.032

50. Sisay, M. (2020). 3CLpro inhibitors as a potential therapeutic option for COVID-19: Available evidence and ongoing clinical trials. Pharmacological Research, 156, 104779. https://doi.org/10.1016/j.phrs.2020.104779

51. Cao, B., Wang, Y., Wen, D., Liu, W., Wang, J., Fan, G., Ruan, L., Song, B., Cai, Y., Wei, M., Li, X., Xia, J., Chen, N., Xiang, J., Yu, T., Bai, T., Xie, X., Zhang, L., Li, C., ... Wang, C. (2020). A trial of lopinavir-ritonavir in adults hospitalized with severe covid-19. New England Journal of Medicine, 382(19), 1787-1799. https:/ / doi.org/ 10.1056/NEJMoa2001282

52. Yao, T. T., Qian, J. D., Zhu, W. Y., Wang, Y., \& Wang, G. Q. (2020). A systematic review of lopinavir therapy for SARS coronavirus and MERS coronavirus-A possible reference for coronavirus disease-19 treatment option. Journal of Medical Virology, 92(6), 556-563. https:/ / doi.org/10.1002/jmv.25729

53. Ma, C., Sacco, M. D., Hurst, B., Townsend, J. A., Hu, Y., Szeto, T., Zhang, X., Tarbet, B., Marty, M. T., Chen, Y., \& Wang, J. (2020). Boceprevir, GC-376, and calpain inhibitors II, XII inhibit SARS-CoV-2 viral replication by targeting the viral main protease. Cell Research, 30(8), 678-692. https:/ / doi.org/10.1038/s41422-020-0356-z.

54. Tan, Q., Duan, L., Ma, Y., Wu, F., Huang, Q., Mao, K., Xiao, W., Xia, H., Zhang, S., Zhou, E., Ma, P., Song, S., Li, Y., Zhao, Z., Sun, Y., Li, Z., Geng, W., Yin, Z., \& Jin, Y. (2020). Is oseltamivir suitable for fighting against COVID-19: In silico assessment, in vitro and retrospective study. Bioorganic Chemistry, 104, 104257. https://doi.org/10.1016/j.bioorg.2020.104257

55. Wu, C., Liu, Y., Yang, Y., Zhang, P., Zhong, W., Wang, Y., Wang, Q., Xu, Y., Li, M., Li, X., Zheng, M., Chen, L., \& Li, H. (2020). Analysis of therapeutic targets for SARS-CoV-2 and discovery of potential drugs by computational methods. Acta Pharmaceutica Sinica B, 10(5), 766-788. https:// doi.org/10.1016/j.apsb.2020.02.008

56. Wong, K. B., Wan, D. C. C., \& Chow, H. F. (2014). Substrate specificity and rational design of peptidomimetic inhibitors for SARS coronavirus main protease. Hong Kong Medical Journal, 20(4), 18-21.

57. Kumar, V., Shin, J. S., Shie, J. J., Ku, K. B., Kim, C., Go, Y. Y., Huang, K. F., Kim, M., \& Liang, P. H. (2017). Identification and evaluation of potent Middle East respiratory syndrome coronavirus (MERS-CoV) 3CLPro inhibitors. Antiviral Research, 141, 101-106. https:// doi.org/10.1016/j.antiviral.2017.02.007

58. Tomar, S., Johnston, M. L., John, S. E. S., Osswald, H. L., Nyalapatla, P. R., Paul, L. N., Ghosh, A. K., Denison, M. R., \& Mesecar, A. D. (2015). Ligand-induced dimerization of Middle East Respiratory Syndrome (MERS) Coronavirus nsp5 protease (3CLpro): Implications for nsp5 regulation and the development of antivirals. Journal of Biological Chemistry, 290(32), 19403-19422. https://doi.org/10.1074/jbc.M115.651463

59. Vagner, J., Qu, H., \& Hruby, V. J. (2008). Peptidomimetics, a synthetic tool of drug discovery. Current Opinion in Chemical Biology, 12(3), 292-296. https:/ / doi.org/10.1016/j.cbpa.2008.03.009

60. Ghosh, A. K., Xi, K., Ratia, K., Santarsiero, B. D., Fu, W., Harcourt, B. H., Rota, P. A., Baker, S. C., Johnson, M. E., \& Mesecar, A. D. (2005). Design and Synthesis of Peptidomimetic Severe Acute Respiratory Syndrome Chymotrypsin-like Protease Inhibitors. Journal of Medicinal Chemistry, 48(22), 6767-6771.

61. Dai, W., Zhang, B., Jiang, X.-M., Su, H., Li, J., Zhao, Y., Xie, X., Jin, Z., Peng, J., Liu, F., Li, C., Li, Y., Bai, F., Wang, H., Chen, X., Cen, X., Hu, S., Yang, X., Wang, J., ... Liu, H. (2020). Structure-Based Design, Synthesis and Biological Evaluation of Peptidomimetic Aldehydes as a Novel Series of Antiviral Drug Candidates Targeting the SARS-CoV-2 Main Protease. https:// doi.org/ 10.1101/2020.03.25.996348

62. Boras, B., Jones, R. M., Anson, B. J., Arenson, D., Aschenbrenner, L., Bakowski, M. A., Beutler, N., Binder, J., Chen, E., Eng, H., Hammond, J., Hoffman, R., Kadar, E. P., Kania, R., Kimoto, E., Kirkpatrick, M. G., Lanyon, L., Lendy, E. K., Lillis, J. R., ... Allerton, C. (2020). Discovery of a Novel Inhibitor of Coronavirus 3CL Protease as a Clinical Candidate for the Potential Treatment of COVID-19. BioRxiv, 2020.09.12.293498. https:// doi.org/10.1101/2020.09.12.293498

63. Ma, C., Sacco, M. D., Hurst, B., Townsend, J. A., Hu, Y., Szeto, T., Zhang, X., Tarbet, B., Marty, M. T., Chen, Y., \& Wang, J. (2020). Boceprevir, GC-376, and calpain inhibitors II, XII inhibit SARS-CoV-2 viral replication by targeting the viral main protease. Cell Research, 30(8), 678-692. https:/ / doi.org/10.1038/s41422-020-0356-z.

64. Zhang, L., Lin, D., Kusov, Y., Nian, Y., Ma, Q., Wang, J., Von Brunn, A., Leyssen, P., Lanko, K., Neyts, J., De Wilde, A., Snijder, E. J., Liu, H., \& Hilgenfeld, R. (2020). $\alpha$-Ketoamides as Broad-Spectrum Inhibitors of Coronavirus and Enterovirus Replication: Structure-Based Design, Synthesis, and Activity Assessment. Journal of Medicinal Chemistry, 63(9), $4562-4578$. https:// doi.org/10.1021/acs.jmedchem.9601828

65. Zhang, L., Lin, D., Sun, X., Curth, U., Drosten, C., Sauerhering, L., Becker, S., Rox, K., \& Hilgenfeld, R. (2020). Crystal structure of SARS-CoV-2 main protease provides a basis for design of improved a-ketoamide inhibitors. Science, 368(6489), 409-412. https://doi.org/10.1126/science.abb3405

66. McAuley, J. L., Gilbertson, B. P., Trifkovic, S., Brown, L. E., \& McKimm-Breschkin, J. L. (2019). Influenza virus neuraminidase structure and functions. Frontiers in Microbiology, 10(JAN). bttps:/ / doi.org/ 10.3389/fmicb.2019.00039

67. Since January 2020 Elsevier has created a COVID-19 resource centre with free information in English and Mandarin on the novel coronavirus COVID-19. The COVID-19 resource centre is hosted on Elsevier Connect, the company's public news and information. (2020). January.

68. Dai, W., Zhang, B., Jiang, X. M., Su, H., Li, J., Zhao, Y., Xie, X., Jin, Z., Peng, J., Liu, F., Li, C., Li, Y., Bai, F., Wang, H., Cheng, X., Cen, X., Hu, S., Yang, X., Wang, J., ... Liu, H. (2020). Structure-based design of antiviral drug candidates targeting the SARS-CoV-2 main protease. Science, 368(6497), 1331-1335. https:// doi.org/10.1126/ science.abb4489 


\begin{abstract}
ABOUT STUDENT AUTHORS
Alyssa Sanders is a senior at Rowan University, graduating with a B.S. in Translational Biomedical Science. She intends to pursue a Ph.D. degree following her graduation.
\end{abstract}

Samuel Ricci is a graduate of Rowan University with a B.S. in Biophysics. He is currently advancing his training as an NIH Intramural Research Training Award recipient in the laboratory of Dr. Christine Alewine at the National Cancer Institute.

Sarah Uribe graduated from Rowan University in May of 2020 with a B.S. in Translational Biomedical Science. She is pursuing her M.S. in Pharmaceutical Science at Rowan University.

Bridget Boyle graduated from Rowan University in May of 2020 with a B.S. in Translational Biomedical Science. Bridget is currently pursuing a Ph.D. degree at Thomas Jefferson University with a focus on neuroscience.

Brian Nepper graduated from Rowan University in May of 2020 with a B.S. in Physics. He is currently perusing a M.S. in Mechanical Engineering at Rowan University with a focus on nanotechnology.

\title{
PRESS SUMMARY
}

The coronaviruses plaguing humanity in the 21 st century share much in common: a spontaneous route of origin from wild animals, a propensity to take human life, and, importantly, a highly conserved set of biological machinery necessary for viral replication. Most recently, the SARS-CoV-2 is decimating economies around the world and has claimed over two million human lives, reminding the world of a need for an effective drug against present and future coronaviruses. To date, attempts to repurpose clinically approved antiviral medications show minimal promise, highlighting the need for development of new antiviral drugs. While vaccines attempt to help the body form antibodies against the viral spike protein, vaccines will be unlikely to protect against future emerging strains. The main protease of the coronavirus is an attractive alternative target for developing broad-spectrum inhibitors that may help protect against future outbreaks. This protease is responsible for cleaving proteins needed to replicate the virus. Here, we review the literature regarding potential inhibitors for the main protease of coronaviruses-with a specific focus on SARS-CoV-2. We analyze receptor-drug interactions and draw conclusions about candidate inhibitors for future outbreaks. Promising candidates for development of a broad-spectrum coronavirus protease inhibitor include the neuraminidase inhibitor $3 \mathrm{k}$, the peptidomimetic inhibitor $11 \mathrm{~b}$, the $\alpha$-ketoamide inhibitor $13 \mathrm{~b}$, the aldehyde prodrug, and the phosphate prodrug developed by Pfizer. In silico and in vitro analysis show that these inhibitors strongly interact with the active site of the main protease, and to varying degrees, prevent viral replication via interactions with the largely conserved active site pockets. 